\title{
Intelligent Agent based Flight Search and Booking System
}

\author{
Floyd Garvey \\ Mona Institute of Applied Science \\ University of West Indies, Kingston, Jamaica
}

\author{
Suresh Sankaranarayanan ${ }^{1,2}$ \\ ${ }^{1}$ Computing \& Information System, \\ ${ }^{1}$ Institut Teknologi Brunei, Brunei \\ ${ }^{2}$ Department of Computing \\ ${ }^{2}$ University of West Indies, Kingston, Jamaica
}

\begin{abstract}
The world globalization is widely used, and there are several definitions that may fit this one word. However the reality remains that globalization has impacted and is impacting each individual on this planet. It is defined to be greater movement of people, goods, capital and ideas due to increased economic integration, which in turn is propelled, by increased trade and investment. It is like moving towards living in a borderless world. With the reality of globalization, the travel industry has benefited significantly. It could be said that globalization is benefiting from the flight industry. Regardless of the way one looks at it, more persons are traveling each day and are exploring several places that were distant places on a map. Equally, technology has been growing at an increasingly rapid pace and is being utilized by several persons all over the world. With the combination of globalization and the increase in technology and the frequency in travel there is a need to provide an intelligent application that is capable to meeting the needs of travelers that utilize mobile phones all over. It is a solution that fits in perfectly to a user's busy lifestyle, offers ease of use and enough intelligence that makes a user's experience worthwhile. Having recognized this need, the Agent based Mobile Airline Search and Booking System is been developed that is built to work on the Android to perform Airline Search and booking using Biometric. The system also possess agent learning capability to perform the search of Airlines based on some previous search pattern .The development been carried out using JADE-LEAP Agent development kit on Android.
\end{abstract}

Keywords- Agents; Biometric; JADE-LEAP; Android.

\section{INTRODUCTION}

The Airline industry controls the world of travel and this industry alone has managed to reduce the distance between places that are geographically miles apart to merely in hours and minutes. According to investopedia, "Few inventions have changed how people live and experience the world as much as the invention of the airplane". There are thousands of airlines worldwide that cover thousands of miles daily and travel has become an acceptable part of our routine. Therefore, to ensure that we get to where we need on time, individuals have to book flights in advance or have someone book the flights on their behalf. In some situations unless a flight is booked well in advance, then one may have to miss such a flight. As the world progresses in these areas, it has become apparent that technology has to play a key role and hence many individuals use the internet to assist in making world of travel a little easier. We find many persons booking flights, cancelling flights and accessing general information about flights via internet. The technological advancements that we have made over the last ten years have tried its best to make the world of travel a lot easier [1]. Various technologies have been employed over the years to address the varying concerns of the travel industry [1]. Still we see yearly in each winter airports in Europe, England and even North America getting jammed with persons, because of cancelled flights and consequently individuals sleep at airports. All these are normally caused by bad weather. However, a lot of this could have been aborted if these travelers had the technological means to manage their flight experiences in a better way. When we look closer home within the Caribbean, we might not suffer from snowstorms that leave our airports inundated but we experience lengthy delays and cancelled flights. With these as background, we here have developed an Intelligent Agent based Mobile system that can provide users the capability to search and book flights and additionally avail enough information so that users of this system will not have to sleep in airports. This system also provides an additional component to users with the capability to see the reviews of airlines and the services so that they might not have to make a mistake that probably was made by someone else and already noted. The system possesses unique feature of booking flights using mobile handset with Biometrics to avoid frauds in credit card payment. However, before going into the details of the system developed, we would first review in brief about some existing Airline Reservation systems in vogue in section 2. Section 3 provides some introduction to Intelligent Agents followed by Agent learning, AI in Flight reservation and biometrics. Section 4 gives the details on the proposed Intelligent Agent based Flight search and booking architecture followed by flowchart and algorithm. Section 5 gives the implementation and validation details using JADE-LEAP and Android 2.2 with Google Maps API. Section 6 is the conclusion and future work.

\section{REVIEW OF AIRLINE RESERVATION SYSTEMS}

The history of the Computer Reservation Systems (CRS) in Airline industry dates back to 1970s when airlines began modifying and enhancing their internal reservation systems to make the sale of airline tickets through travel agents more efficient. The CRS gave travel agents access to information about flight schedules, fares, and seat availability. It also enabled them to make reservations and issue of tickets automatic. Although the computer reservation systems are owned and operated by particular airlines, travel agent can use 
one to get information and make reservations on virtually any scheduled carrier [2]. Since the system, make both airlines and travel agents more productive, CRS owners charge both of them for the use of their systems. Travel agents rent the equipment, while airlines pay a booking fee for each flight reservation. American Airlines introduced the first computer reservation system; United, TransWorld, Eastern, and Delta each followed with systems of their own. American and United, however, dominate the CRS industry; in 1986, they accounted for 41 percent and 33 percent, respectively, of the flight segments booked through computer reservation system [2].

A great majority of these airlines have online web based system as most persons such as business travelers and persons technically inclined to facilitate their travelling process by booking flights online. It is because of the large increase in the amount of persons that travel gave rise to the Online Reservation System. The modern airline reservation system is a comprehensive suite of products to provide system that assists with variety of airline management tasks and service customer needs from the time of initial reservation through completion of the flight [3]. Now with the advent of tremendous development in mobile technology, we see many people searching and booking flights using their mobile handset. There is also talk about receiving tickets and boarding pass on mobile to make airline ticket booking paperless. There has been some application developed in terms of Flight booking on the latest Android handset such as; Kayak, CheckMyTrip Mobile Companion, Pageonce Travel, Flight Trip Planner and TripIt. But many of these applications are mobile versions to websites only that provide services like flight booking, location information, weather information and information of the destinations like hotels, restaurants, gas stations, cinemas and so on similar to any online web based Airline search system

The booking of flights using a mobile phone has become extremely popular over the last half decade. As smart phones became popular, reserving flights via mobile phone was introduced. However, there were some challenges in booking flights via mobile devices, which has proved a logistical challenge for technology providers in the managed travel space. Though search is good in terms of returning results, the search is more brute force as opposed to intelligence. The search results are returned by querying the database built on the user criteria. The search most often times is not refined by the software and it is left to the user to refine the search to retrieve the most appropriate results by sitting in front of the computer connected to internet or from the mobile. After results returned, the user is left with the task to mine through all this information after which the choice is then made or if the search is not sufficient perform other searches until the result is satisfactory. This puts lots of work on the user though the search operation is carried out by the search algorithm.

Now to book a flight users have to use their credit cards by inputting the details online with all their related information. According to Scamwatch, victims have reported losses of more than a $\$ 1000$ for fake international flight bookings and instances of identity theft [4]. Though many online airline web systems take extreme care in securing the financial details for booking, still there are some discrepancies in the system that lead to fraud and identity theft. With all this in mind one has to be careful of how booking is done as there are several sites that exist that basically mimic real sites so the concept of booking flights online by entering all your information in view of the security challenges that currently exist is not ideally safe. So with all these in mind, we here have developed Intelligent Agent based Flight Search and booking system [5] which searches the Airline based on user criteria and makes intelligent decision rather than leaving to the user to make decision. Also booking flight been carried out using Biometrics to avoid credit card fraud. However, before going into those details, we will review in brief about Intelligent Agent technologies followed by AI in flight Reservation system and biometrics.

\section{INTELLIGENT AGENTS}

Agent technology has emerged as formidable IT area. Agents can be defined to be autonomous, problem-solving computational entities capable of effective operation in dynamic and open environments [6-10]. An agent is something that acts in an environment. For agents to be classified as intelligent they not only must exhibit intelligent behavior but they must have the ability to learn and follow similar patterns of learning. Learning is defined to be the acquisition of knowledge or skills through experience, practice, or study, or by being taught [11][12]. Learning is done by humans, animals and some machines. In order for an agent to learn, they must be able to act intelligently. The concept of Agent Learning and the consequent artificial intelligence is not new [13][14]. Since that time, hundreds if not thousands, of articles have been published on the topic, and at least two books [15 - 20]

\section{A. Artificial Intelligence in Flight Reservation Systems}

Artificial Intelligence (AI) is the key technology in many of today's novel applications, ranging from banking systems that detect attempted credit card fraud, to telephone systems that understand speech, to software systems that notice when you are having problems and offer appropriate advice. These technologies would not exist today without the sustained federal support of fundamental AI research over the past three decades [21]. The area of flight reservation systems is no exception to the existence of artificial intelligence. Many airlines have opted to divest most of their holdings to Global Distribution Systems (GDS) due to which many systems are now accessible to consumers through Internet gateways for hotels, car rental agencies, and other services as well as airline tickets. A traveler or a travel agent can chalk out an itinerary using a GDS which is a global system interconnecting airlines, hotels, travel agents, car rental companies, cruise liners etc. [22].

There are four major Global Distribution Systems, and they are AMADEUS, GALILEO, SABRE and WORLDSPAN. The SABRE reservation system is used by American Airlines and boasts an intelligent interface named PEGASUS, which is a spoken language interface, connected to SABRE which allows subscribers to obtain flight 
information and make flight reservations via a large, on-line dynamic database accessed through their personal computer over the telephone.

As the technology advances and more persons are becoming smart phone users, the need exists to give internet users from desktops, laptops and smart phones the ability to search for flights and to book flights online. Therefore, we have several applications that have given users the ability to work on smart phones such as blackberries, iphone and android. One of the major concerns for Smartphone users is the actual booking of the flight because this includes the use of credit cards and with the many incidents of identity theft and fraud over the internet, this raises a red flag. However, we offer in this paper, to prospective users a secure environment to do these transactions without worry or concerns. However, before going into those details, we look in brief about Biometrics.

\section{B. Biometrics}

Biometrics is the science and technology of measuring and analyzing biological data. In information technology, biometrics refers to technologies that measure and analyze human body characteristics, such as DNA, fingerprints, eye retinas and irises, voice patterns, facial patterns and hand measurements, for authentication purposes [23]. In this research area of biometrics, we will focus on fingerprint capture, verification and encryption [24-26]. Biometric is a standard now that all laptops come with biometric security options that give users the ability to store their passwords as biometric imprints and $\log$ onto their devices using their fingers as opposed to typing in passwords in a traditional way.

We will now present the details of how biometric data is captured and verified. To convert the biometric input, a software application is used to identify specific points of data as match points. The match points in the database are processed using an algorithm that translates that information into a numeric value. The database value is compared with the biometric input from the end user who has entered into the scanner and authentication is either approved or denied [23]. In order to enroll a fingerprint several steps are performed [27] as shown in Fig 1. Therefore, we see the use of biometrics as a very secure way of implementing security in a system that users' private and sensitive data are being accessed and want to keep out of unauthorized personnel to prevent identity theft. It has been seen from the literature that work has been done in the use of AI in flight reservation systems and technologies been used to avoid identity fraud in payment. But in all the above system AI search algorithms, being used to perform the search of airlines with some intelligence and also security has been used to avoid credit card theft in payment. But still the system lacks intelligence and smartness in searching of airlines where again the burden falls on the user towards refining the search, making decision based on retrieved results. The system also possesses no facility of searching based on past experience or so. Also the system gives no information on the rating of airlines and so. In addition to search, there still exist challenges to facilitate a secure platform that users can trust to carry out their transaction in a technical space free from interference. The applications that exist are good but in many of the instances, they provide real time flight information to prospective clients and facilitate payment with the use of third party intervention. All these systems been developed as web based only which can be accessed from desktop or mobile and not for mobile handset as such. These drawbacks that exist can be accomplished by means of intelligent agent which is however seen that no research exists or been carried out towards airline reservation and booking system.

Our proposed system [5] so allows the users to search for airline based on their preference using intelligent agent to make intelligent decision and display on mobile handset by applying fuzzy preferences. Also, extend the Intelligent Search Agent with learning capability that may be searching for a flight with minimal individual preferences based on previous search experience of the agent. System also aims to protect users from identity theft and fraud by providing a platform to validate airline based on flight selection by user and facilitate booking and cancellation of flights by customers using their own credit cards using biometric and encryption technology to ensure a secure platform.

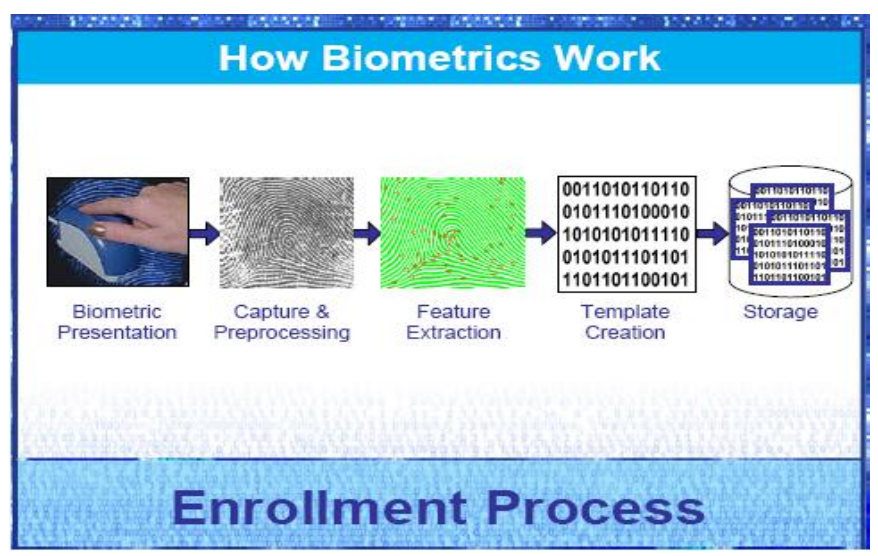

Figure 1 Biometric Enrollment Process

\section{InTELLIGENT AGENT BASED FLIGHT SEARCH AND SECURED BOOKING ARCHITECTURE}

The Intelligent Agent based Search and secured Booking system i.e. IABFS-SBS [5] developed surrounds two important facets of the travel industry, which includes search for flights and booking the flights, which includes payment part. When a search is done by means of agent, which is replication of travel agent, it is important that the optimum results are returned to the user. Another factor to be considered is that the search must be efficient, quick and it must return only what is asked for which will prevent the user from spending a lot of time skimming through unnecessary information as it exists in the current system. Fig 2 depicts the search process flow in our system developed.

The booking of flights via a mobile device is similar to booking flights via a website but what is different is that in this situation we are not booking flights via the mobile device by accessing a website directly and doing the work just as we would if we were using our desktop or laptop computers. In 
order to successfully do this we have several factors to keep in mind such as; Security, Third Party Connectivity Channels, Encryption Mechanism, Biometric Implementation which forms a crucial part of the security platform. In addition, the booking of flight involves the usage of a customer's credit card, which includes confidential information. With this in mind, care has to be taken on how a customer transaction is processed via the mobile device as shown in Fig.3. We will now explain the roles and responsibilities of each component in the architectures shown in Figs 2 and 3.

\section{1) Human Agent-}

The human agent is the end user that is interested in searching for flights using this platform. This agent is the individual operating on the android mobile handset based on different criteria input in the system by this agent. Different queries are constructed and search is executed on the central database and the required results are returned to the human agent for viewing for proceeding with further search and executing the action of booking a flight.

\section{2) Mobile Device -}

The mobile device is the android handset that the application is installed on, and the human agent is using to perform search operations and booking operations. Additionally the device could be utilized to just view daily arrivals and departures.

\section{3) Search Agent -}

The Search Agent is assigned the roles and responsibilities such as: Construct Queries based on the user input., Query the central database for user information based on the query that was constructed., Return results of search to the device for the user's viewing., Sort the information so that they are returned to the user in an organized matter., Send user choice to Airline Agent if user is interested in booking a flight so that the airline can be validated.

\section{4) Airline Agent -}

The Airline Agent is assigned the roles and responsibilities such as: The airline agent validates the airline website as a first security measure before the system proceeds with the booking process., Transmits information to user when the airline has been validated., Receives booking and cancellation information from other agents., Updates airline database with booking or cancellation references., Ensures that when flight is booked user's flight information is reserved with airline.

\section{5) Security Agent -}

The Security Agent is assigned the roles and responsibilities such as: The security agent facilitates the reading of fingerprints and the encryption of fingerprint information. Communicates with trusted third party to transmit secure information such a biometric data or user encrypted payment information to airline agent., Establishes HTTPS SSL connection to ensure secure transfer of biometric information., Establishes HTTPS SSL connection with card agent to ensure secure transfer of user encrypted information to facilitate payment., Establish secure https SSL connection with airline agent to obtain certificate for trust verification., Receives passenger booking status verification results and securely transfers over https connection results to the search agent for presentation to the passenger.

\section{6) Card Agent -}

The Card Agent is assigned the roles and responsibilities such as : Receives payment or cancellation request accompanied with user encrypted information for processing of payment or cancellation., Establish secure https SSL connection with card companies to facilitate secure payment or cancellation of payment., Transmits status of payment or cancellation via https SSL connection to security agent.

\section{7) Learner Agent -}

The Leaner Agent is assigned the roles and responsibilities such as: The agent studies the search patterns of various users and constructs a pattern based on user's travel pattern. The agent is able to perform search based on learnt behavior and return results that the user would have chosen., The agent communicates the learnt behavior with the search agent to construct queries to perform on the central database.

\section{8) Trusted Third Party -}

The external trusted third party is assigned the roles and responsibilities such as: Securely liaise via https with Security Agent and Airline Agent to validate airline., Securely liaise with the security agent to receive biometric and encrypted information for validation purposes., Securely liaise with card agent to facilitate secure payment for booking of flight, Securely liaise with card agent to facilitate secure cancellation of flight, Securely verify applicant identity using encrypted biometric data.

\section{9) Directory facilitator -}

This is an integral part of the agent platform that operates by providing yellow page services to other agents. The DF maintains an accurate, complete and timely list of agents and must provide the most current information about agents in its directory to all authorized agents [29]

\section{B. IABS-SBS Algorithm}

The process flow of Intelligent Agent Based Search and Secured Booking Flight System has been shown as Flow Charts in Figs 4 \&.5. We will expand this by providing an explanation of how this works. Initially the User accesses the application from the mobile android handset. The user has the option to view arrivals, view departures, search for flights and perform booking. Other sessions are as under.

\section{1) Arrivals -}

User selects Arrivals to view the latest information on arrivals available in the system.. The information is displayed to the user organized according to dates., When user selects one of the flights being displayed under any date displayed., Details of the selected flight are displayed.

\section{2) Departures -}

User selects Departures to view the latest information on departures available in the system. The information is displayed to the user organized according to dates., When user selects one of the flights being displayed under any date displayed., Details of the selected flight are displayed.

\section{3) Search and Booking-}


User enters search criteria from a GUI on mobile device (Intelligent Agent) such as Departure and Arrival city using GMAP, price, percentage markup, rating, facilities etc., Upon submission the search criteria is passed to the Search agent that starts the search process sending the request to the central database to look up a list of suitable airlines matching the search criteria as :

(i) If airline is available for lower price range with exact or closest departure and arrival city matching the amenities, (ii) If airline is available for the price range specified with exact or closest departure and arrival city matching amenities, (iii)If no airlines available within the price range or so for exact or closest departure and arrival city, it finds an airline with the facilities for any price range.

Now the search agent interacts with a database that in turn forwards the results to the user along with the rating and popularity information., The search agent returns the result and displays it on the GUI of the mobile devices., From the detail screen user selects to book the flight., Search agent contacts the security agent for validating the airline agent., After verification, details of flight including price and other pertinent information is displayed to user for confirmation., After user confirms the information, user is asked to enter fingerprint information to begin the payment process., User swipes finger, after which the fingerprint is encrypted and transmitted to security agent who verifies the user over HTTPS SSL connection by contacting the card agent., After verification data is transmitted to card agent over HTTPS SSL connection to process payment., Card agent facilitates payment via a HTTPS SSL connection and then uses a similar connection to send status to security agent., Security agent communicates with airline agent the status of payment who in turn updates airline database with reservation details and Information is sent to the device and user is presented with an update and reference details.

\section{4) Cancellation -}

User selects status from device which presents option to view flight status or cancel flight., User selects flight cancellation; this presents the option for user to enter booking reference and biometric signature which is user's fingerprint,, Booking reference is verified against fingerprint for validation., Once verification is complete, the fingerprint is encrypted and the airline is verified through the airline agent. Once airline is identified data is sent to security agent for verification., once verification is done security agent connects airline agent with card agent., User verifies transaction and accepts cancellation policy., Ticket is cancelled and a status is sent to the mobile handset for the user's viewing

\section{Ratings and Popularity Index}

The system is built with a ratings and popularity index feature to assist clients and prospective clients to be able to make informed decisions about their choice of flight and also after they have used the services of any airline they are able to provide feedback as to the services that were offered and provide ratings as to how good were these services.

\section{1) Ratings:}

The ratings of an airline are divided into a few categories and they are; Infrastructure, cleanliness, security, facilities, price, snacks and ground staff. All these areas are rated out of five stars with one star being the lowest and five stars being the highest meaning the service is excellent. The results from these different areas when collected are then averaged to arrive at a final rating value. So when there are ratings of a particular airline for example four stars, this result is based on the average as calculated from the areas mentioned earlier.

\section{2) Popularity Index:}

The popularity index of any airline is based on the average of the amount of times persons have booked and travelled the airline. The value for the PI ranges from 1 to 5 and follows the following interpretation where percentage indicates the number of persons opting for the airline in a particular sector.

$>1$ is Poor : $0 \%$ and above to less than $15 \%$

$>2$ is Satisfactory: $15 \%$ and above to less than $30 \%$

$>3$ is Average: $30 \%$ and above to less than $50 \%$

$>4$ is Good : $50 \%$ and above to less than $80 \%$

5 is Excellent: $80 \%$ and above

\section{IMPLEMENTATION USING JADE-LEAP}

The main purpose of IABFS-SBS is to enable travelers to search for flights according to user specification and also book online using biometric. The system is also equipped to view the Flight departure and arrival information and also how well the services are viewed by their customers. The system is created using Android 2.2 with Google API 8 and Java Agent Development Toolkit (JADE) with Lightweight Extensible Authentication Protocol (LEAP) [28-31]. The list of all agents implemented in this system is shown below in Fig.6. The abbreviated names that were introduced when giving details of the agents' functionality is used.

\section{A. Flight Search Implementation}

The user normally would access the systems interface and select the Flight search option to initiate a flight search. The search capabilities of the system give the user the ability to perform search for departure and arrival city selection in two ways. The first method allows the user to use the Google map API which loads the Google map within the android environment for selecting the departure and arrival cities as shown in Figs 7 and 8. The other option to select the departure and arrival city is called the wild card search. Users here do not have to use the Google Map option; once they are aware of the city they are travelling to. They just start typing the name of the city. Once the users start typing the name of the city in the textbox field, the search agent immediately starts querying the database for cities that begins with the letters as they are typed. The results immediately appear as a drop down below the text box that the user is typing in. Since there may be several cities with the same name below, each option in the drop down box is a description telling where the city is so that the choice made by user can be more informative as shown in Figs 9 and 10. In this scenario, once the arrival and departure city is selected from the Google map or wild card search, the departure and arrival cities are loaded into the text boxes. 
After that the user is presented with several other criteria such as price, price mark up, facilities like in-flight snacks, Ground service, wheel chair access etc to customize their search as shown in Fig 11a and b. So here once the user selects the criteria with a price of say $\$ 300.00$ with $5 \%$ price markup and other facilities included such as Ground service, In-flight snacks, Airport Shuttle etc and feedback of 3 months, the search agent possess the intelligence to search the database and does not return a list of all flights but tunes the results to match exactly what is being searched for by the user i.e $\$ 300.00$ from Miami to Kingston with facilities included as shown in Fig. 12a. Fig 12band c shows the complete details of flight returned with the average rating of 4 which is Good and popularity index of 5 which means more than $80 \%$ of travelers have opted this airline for this sector Miami to Kingston.

Let us consider another scenario where the user selects the criteria to fly from Miami i.e. Departure city to Portmore i.e Arrival city with a price of say $\$ 500.00$ with price markup of $5 \%$ and all facilities included. Once the search is initiated, the Search agent will look for flights and retrieve the results for Miami to Ocho Rios or Kingston only as there exist no Airports in Portmore and obviously no flights from Miami to Portmore with all other criteria remaining the same.

The search agent here possess the intelligence to return the search results with the price of $\$ 525$ by applying 5\% price markup as per user selection and additionally chooses an airport closest to the city that the user selected which is Kingston and a message is displayed on screen that there is no airport in that city and hence another city is selected. The city selected is the closest one to what placed as a search criteria by the user. Fig 13a and b shows the complete Flight details with the rating of 4 which is Good and popularity index of 5 which shows again $80 \%$ and more travelers have opted this airline for this sector.

\section{B. Intelligent Agent Learning}

Till now we have seen as how the user selects the criteria which includes price, markup and also facilities. The facilities if left blank the agent would take some default value and return the results. So we here bring the learning capability of search agent where it is enough the user gives the basic criteria for search i.e Departure city, Arrival city, Price, Price markup, ratings and other parameters such as Facilities are left as blank. In here the search agent does not search flights taking the default value for facilities but possess the learning capability to search for flights for a particular price with facilities which is most commonly been used by users based on popularity information. This shows the past search experience and learning capability of search agent similar to what we would experience with the human travel agent.

Let us consider a scenario where user is searching flight for price of $\$ 300.00$ with markup of $5 \%$ from Kingston to Toronto by leaving the facilities as blank with feedback of 3 months. The search agent here initiates the learner agent which retrieves the flights from Kingston to Toronto for price of $\$ 300.00$ with facilities based on past search experience or agent learning capability having Excellent rating of 5 and popularity index which means more than $80 \%$ of users have opted this flight for this route and price with facilities as shown in Fig. 15.

Let us consider another scenario where the user is searching for flight from Kingston to London with a price of $\$ 500.00$ with some facilities. The Search Agent was unable to retrieve results that match the criteria requested by user and therefore the Learner Agent uses the past search experience and retrieved a flight with the exact price match of $\$ 500.00$ with any facilities for the route as shown in Fig 16a which is been opted by most user as displayed by the popularity index which is 4 i.e $50 \%$ and more travelers have opted this airline and rating is 4 . Also the Learner agent retrieved the flights for any price with matching facilities for the route as shown in Fig $16 \mathrm{~b}$ which is opted by most users as displayed by popularity index i.e 4 and rating of 4 .

Let us consider last scenario in Agent learning where user is looking for a flight with a price of $\$ 700.00$ from Kingston to Chicago with facilities left as blank. The search agent was unable to retrieve the results and therefore the learner agent was initialized which again could not retrieve flights for the price quoted by the user for that route with facilities with past search experience. So the learner agent uses more intelligence and based on past experience have retrieved flights on that route with any price and any facilities as shown in $17 \mathrm{a}$ and $\mathrm{b}$ having excellent popularity index and rating 4 . The breakdown of rating is shown in Fig.18 comprising of infrastructure, Cleanliness, Security, Facilities, Price, Snacks and Ground Staff

\section{Flight Booking and Payment}

Now that the search is completed, the customer would go about booking the flight of his choice. In here let us take one search agent results as shown in Fig. 15 where there is option to book the flight which the customer selects to book on the android mobile device as shown in Fig.19 The security Agent collects the information from the user and transmits encrypted information to a third party to verify if the Airline website can be trusted or not as shown in Fig.20 by contacting the Airline Agent. After the Airline is successfully verified and validated by the security agent, the Flight information based on user preference is returned to the user from the Airline Agent for confirmation as shown in Fig. 21.

Also the Airline cancellation policy also present to the user to accept for payment processing as shown in Fig.22. Once the user accepts this information and proceeds to book flight, the user is presented with the screen to input details of credit card and present biometric which in our case is the fingerprint. The novelity in our research is that the user need not remember card number or so. The only thing the user needs to know is the credit card type and give his biometric information for transaction as shown in Fig .23.

After the fingerprint is accepted, the system checks to see if the fingerprint is found in the database by contacting the card agent as shown in Fig 24. For that the fingerprint is encrypted and the encryption keys are generated using 256 bit encryption as shown in Fig 25 . Once encrypted, the information is passed onto the security Agent which contacts 
the card agent to see if the Fingerprint is found in the database and the confirmation is sent to user's mobile handset. If the user fingerprint is not available in the database, then it is intimated to user mobile phone as record not found. This could be due to many reasons such as Fingerprint not given properly or user does not possess credit card etc. Once record found based on fingerprint data, the user credit card information is retrieved and displayed along with the final billing amount for the user to confirm and do final payment as shown in Fig 26. Fig 27 shows the payment being processed. Once payment processed successfully, the transaction information is sent to user's mobile handset by the card agent and also updated in database too as shown in Fig .28.

\section{Flight Cancellation}

For cancellation, the user selects the option to search for the flight using the ticket information that they have. After the passenger inputs the booking information and scans their fingerprint, the fingerprint is taken and validated towards refund of money by the Airline to the authenticated passenger, which depends on Airline cancellation policy. For verifying the fingerprint and successfully matching against the booking reference, the fingerprint is encrypted. This is done as the security agent will have to pass this information to the card agent to match against the records that exist for payment because the transaction must be posted against the correct credit card account as shown in Fig 29. The agent from the mobile handset sends request towards verifying the airline agent that is to be used to perform the cancellation as shown in Fig.30. The information is passed to the Security agent as shown in Fig.31 once the airline agent has been identified.

Even though the airline and booking reference is showed, the encrypted finger print is also passed to the Security agent as part of the process to do further checks before forwarded to the appropriate card agent as shown in Fig .32. The information is received by the Security Agent and the SA verifies the AA. After which the AA is connected with the Card Agent (CA) to facilitate the processing of the cancellation. The Card Agent would process the cancellation based on what type of card is used whether MasterCard or Visa. After the Airline Agent has submitted the information to the Card Agent and the card type has been verified there is a two step user verification process where the flight information is displayed to the user to verify to ensure that the correct flight is being cancelled and the correct amount be posted to the account.

The second step of the user verification process is the display of the cancellation policy so that user is reminded of the consequences to cancelling a flight and accepts the policies. If user accepts with the policies then user moves accepting and continuing with the process as shown in Fig.33 After the user accepts the terms and conditions for cancelling the flight the Card Agent proceeds to cancelling the flight by reversing the transaction a shown in Fig.34 The Card Agent cancels the transaction and credits the customer's account and transmits the information to the Airline Agent so that the information can be updated with the airline and in the central database. After the flight is successfully cancelled the status information is sent to the user after which the Airline Agent database and the central database are updated with the flight cancellation information as shown in Fig.35.

There are situations where popularity index is shown as Average that shows that less than $50 \%$ of travelers have only used this airline for a particular sector as shown in Fig .36 which is indicated by means of warning message on user's mobile handset. There is another situation which the user can experience in agent learning results where the popularity is good i.e. $50 \%$ of traveler has opted but rating is below 3 as shown in Fig .37 which is indicated by warning message. Airline Agent interface provide information of ratings and popularity for airlines across various continents. Ratings and Popularity can be viewed for all airlines by continent and based on selected periods, which range from three month periods to up to a year. Database agent sends warning message because some airlines contain below normal values for ratings and popularity and removed from database after period of 3 months.

\section{CONCLUSION \& FUTURE WORK}

With the advancement of technology you find many persons with Smartphone that operates at level and capability of a desktop PC or laptop. Most large corporations today provide Smartphone to managers and supervisors. With all this in mind users are now capable of accessing various applications and services from their mobile devices. Therefore IABFS-SBS seeks to address gaps that exist where persons can continue with their busy life styles and yet book flights, cancel flights, view airline popularity and ratings based on frequency of travel by passengers, view real time arrivals and departures. There are several applications in existence that offers travelers the capability to book flights, and hotel rooms and outline a travel schedule as was previously discussed. However, IABFS-SBS offers to the Android platform specifically the ability to enjoy Intelligent Agent based flight search that has the added facility of agent learning that studies patterns and returns user specific information to the potential passenger. Additionally the system is replete with security, offering biometric encrypted features used when booking or cancelling a flight, which offers potential users enough comfort that even though the operation is being done from a mobile device.

The system provides real time viewing of flight arrivals and departures but this is just for the users viewing as future work. Users could be allowed to select any flight they see in the departure dashboard and book it. Additionally the system is built to provide Intelligent Agent based flight search and secured booking capabilities but as we look at trends with similar applications and similar facilities we may find the need in the future to expand the work and offer potential users a more holistic service in terms of not just flight search and booking but assistance with booking of hotels using agent technology and the popularity and rating module built within the current application. User could also get assistance with taxi reservations. As the android platform increases its capabilities and Smartphone technology get more advanced in the future, the system could look at real time communication 
with its users by sending text messages to advise them of delays, snow storms and airline details being offered. Last but not the least, the system could also facilitate Agent Based mobile check in, so that when users get to the airport things run a little smother.

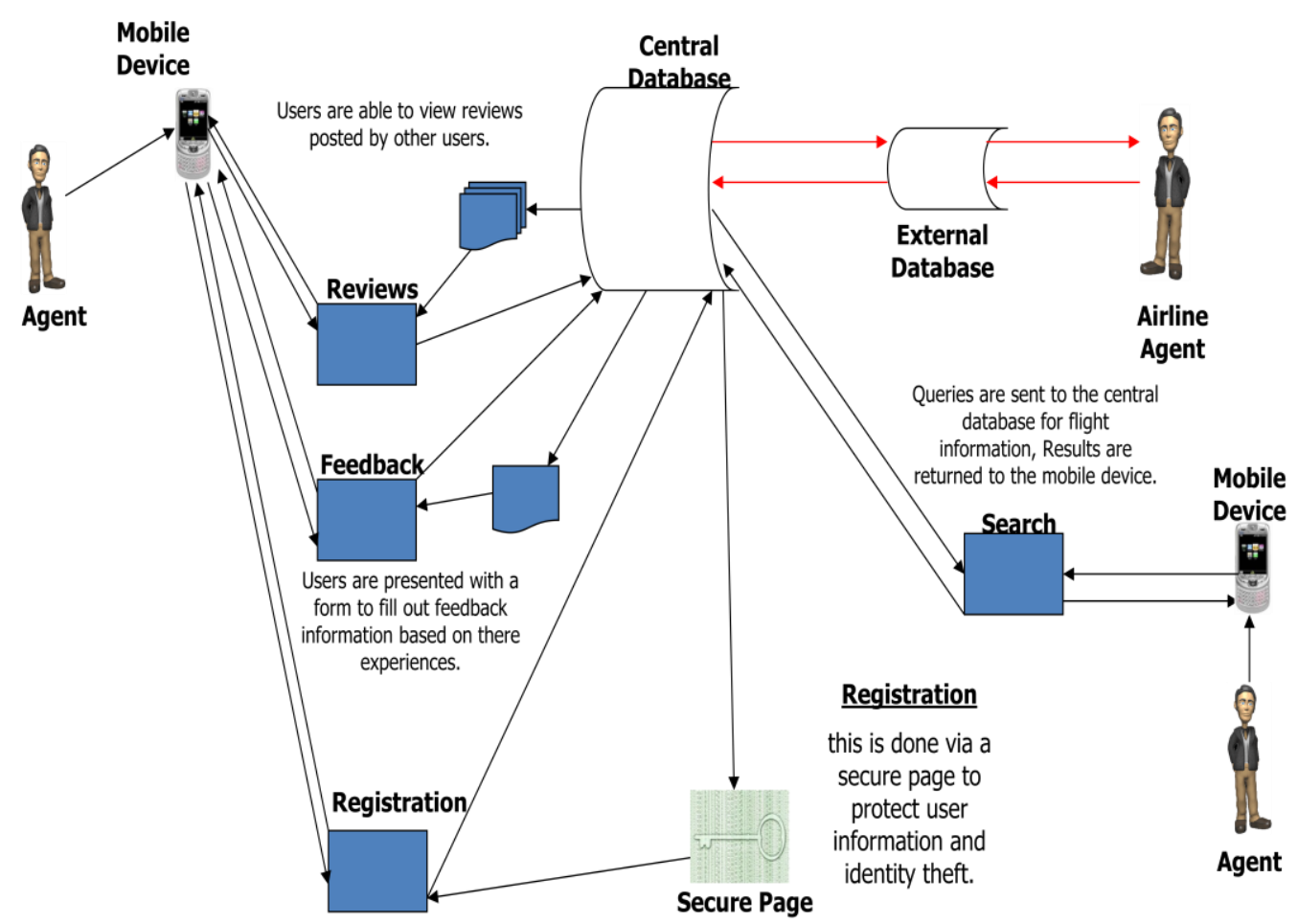

Fig 2 Intelligent Agent based Flight Search

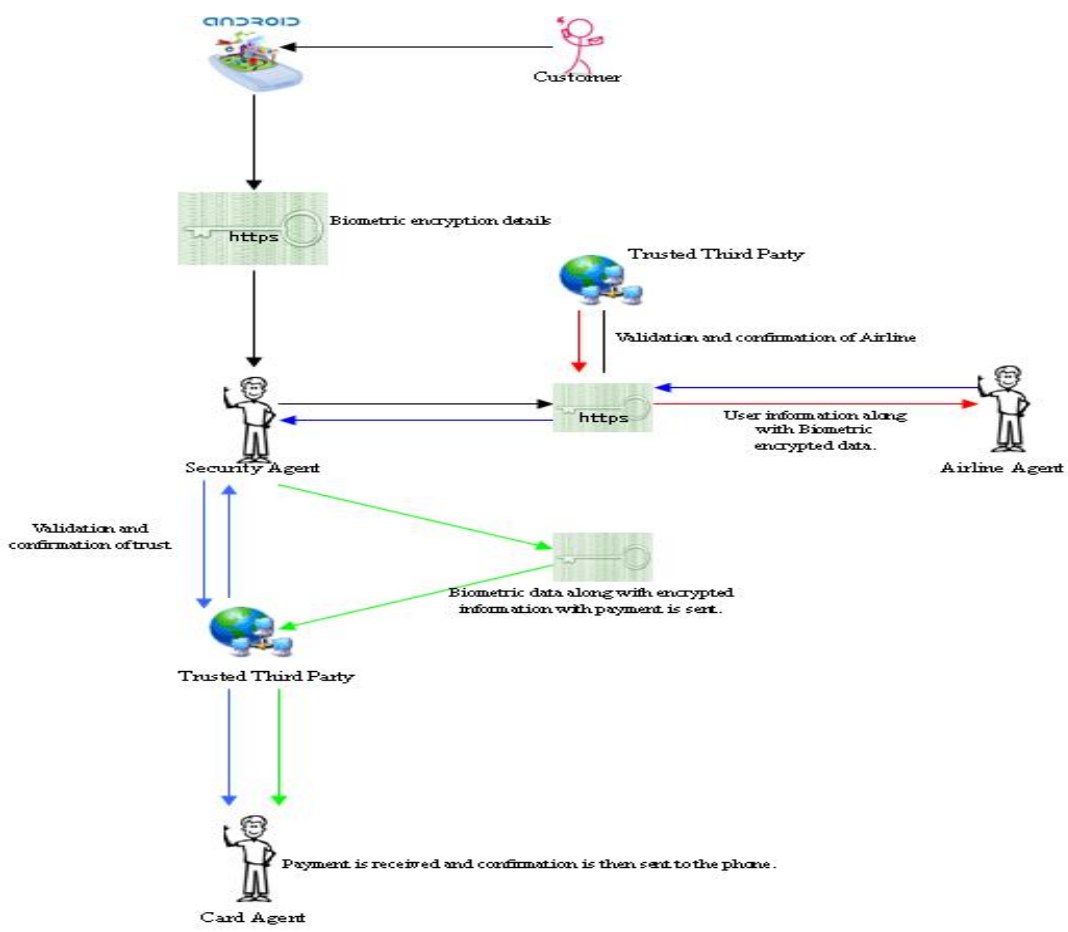

Figure 3 Intelligent Agent based Booking and Payment Architecture

www.ijacsa.thesai.org 


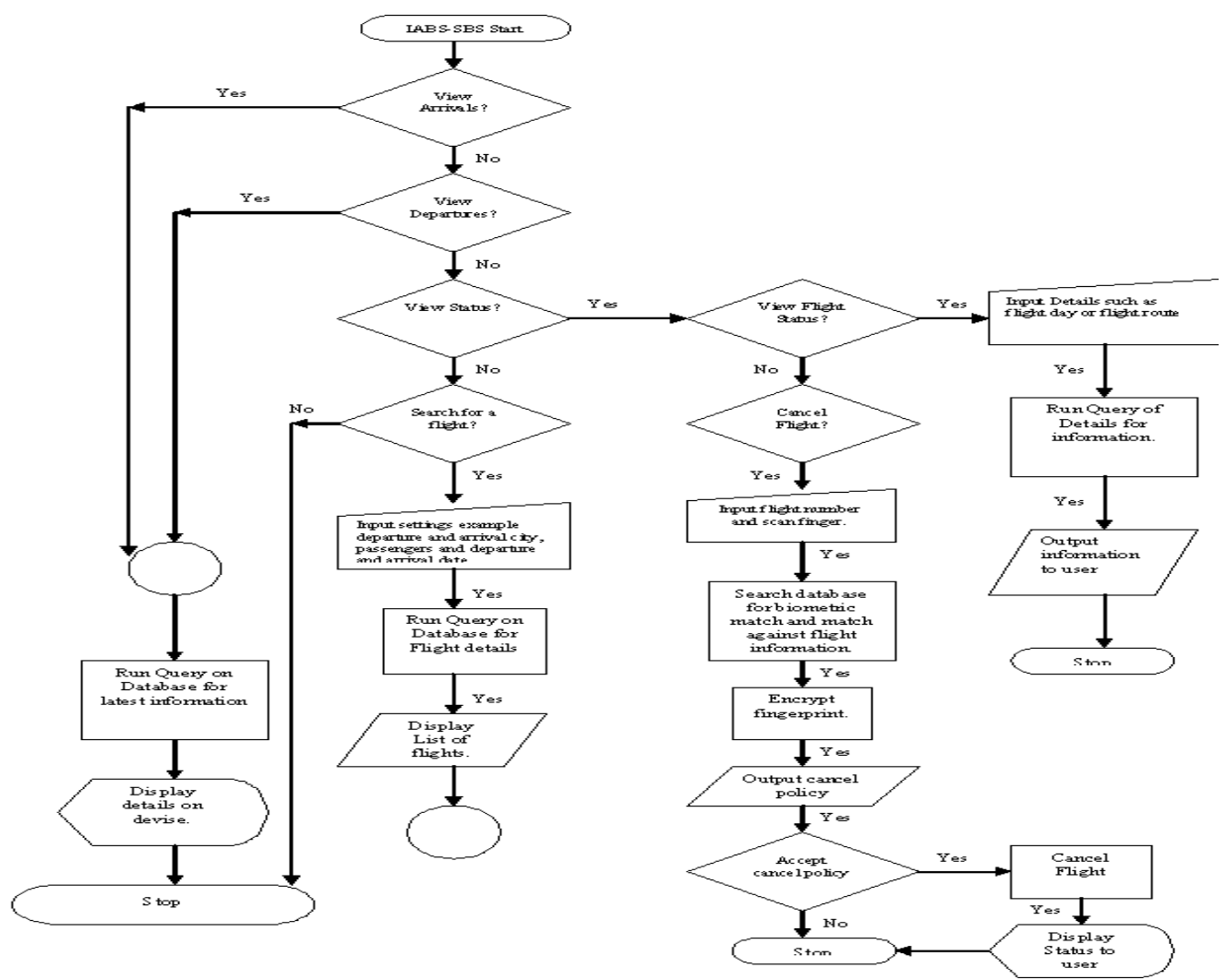

Figure 4 IABS-SBS Process Flow

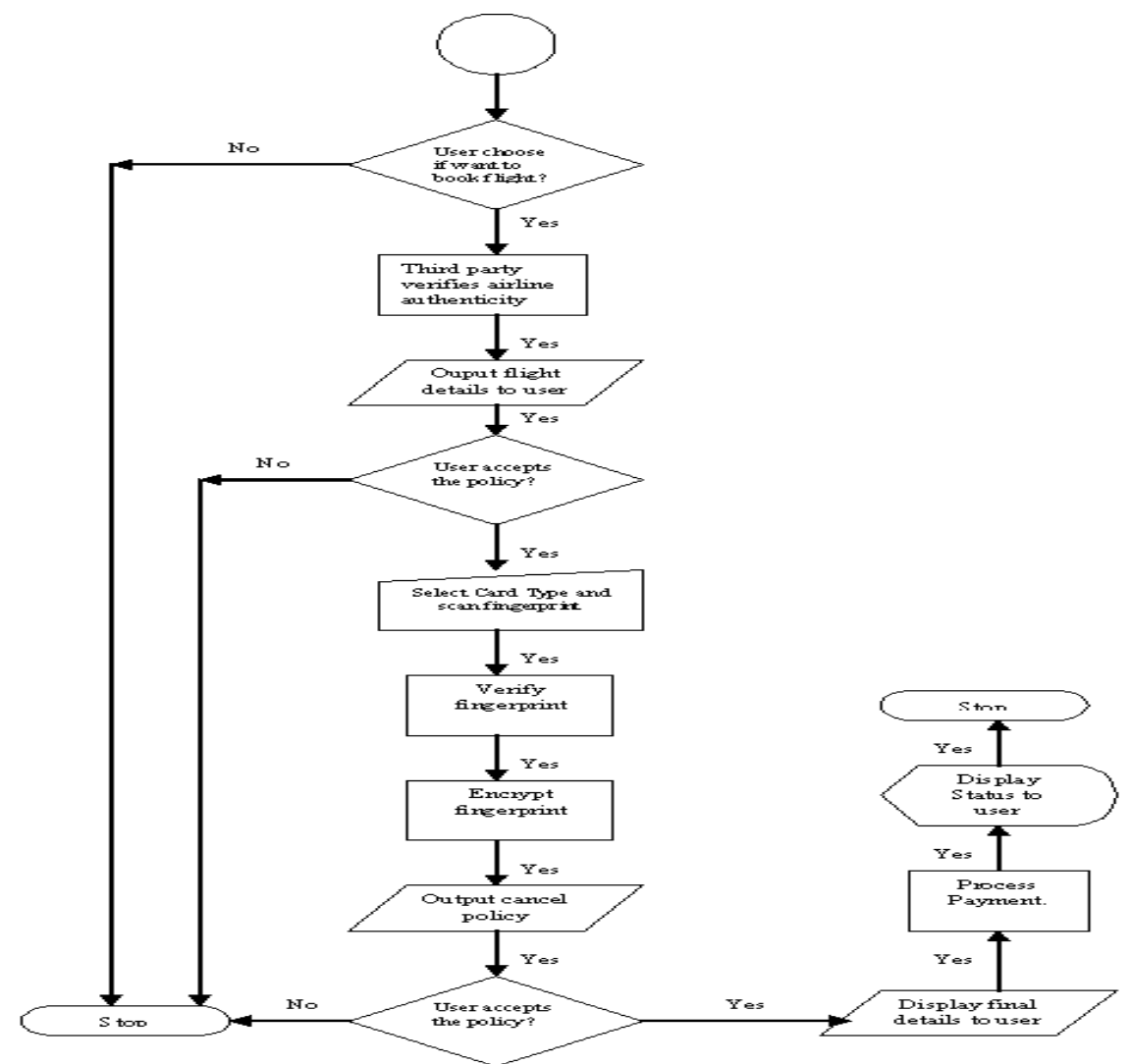

Figure 5 IABS-SBS Process Flow (contd) 


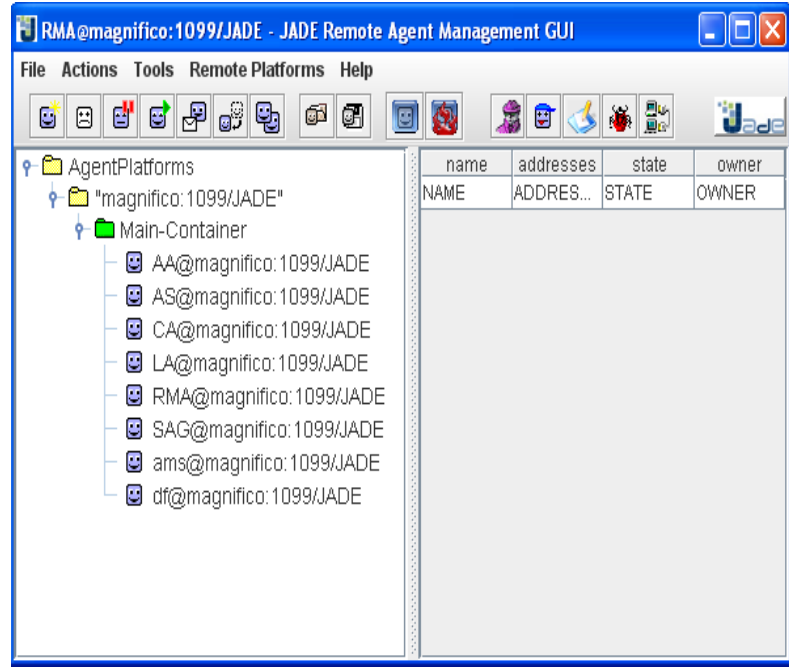

Figure 6 Agents in the JADE Container

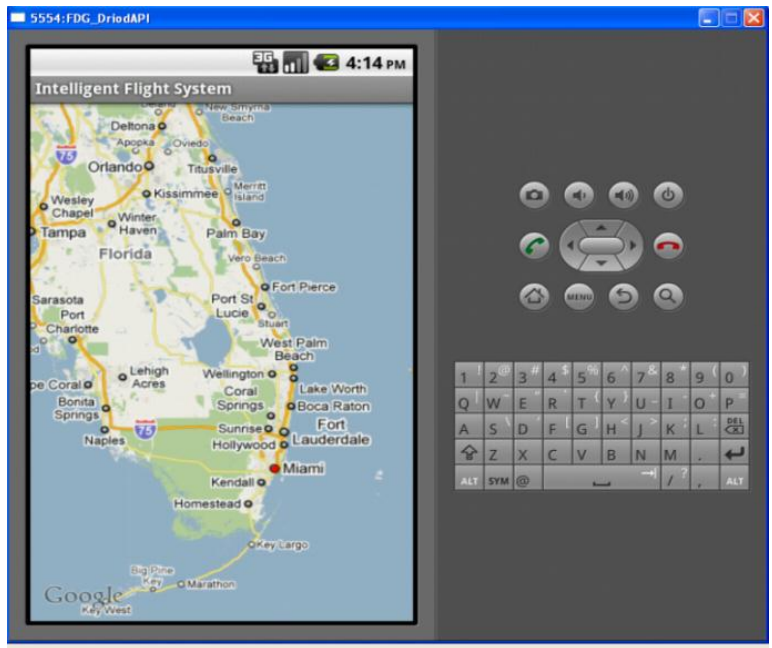

Figure. 7 Arrival City Selection

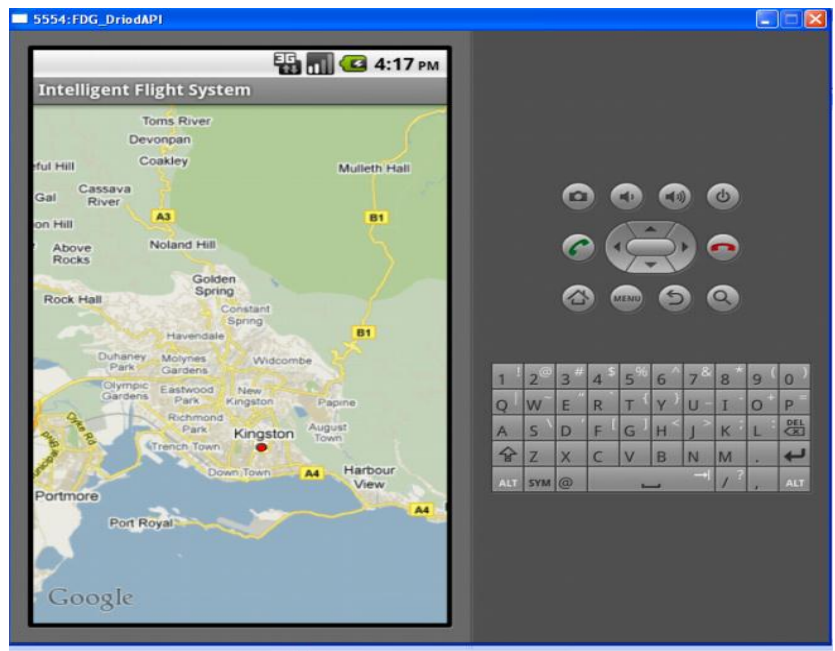

Figure. 8 Departure City Selection

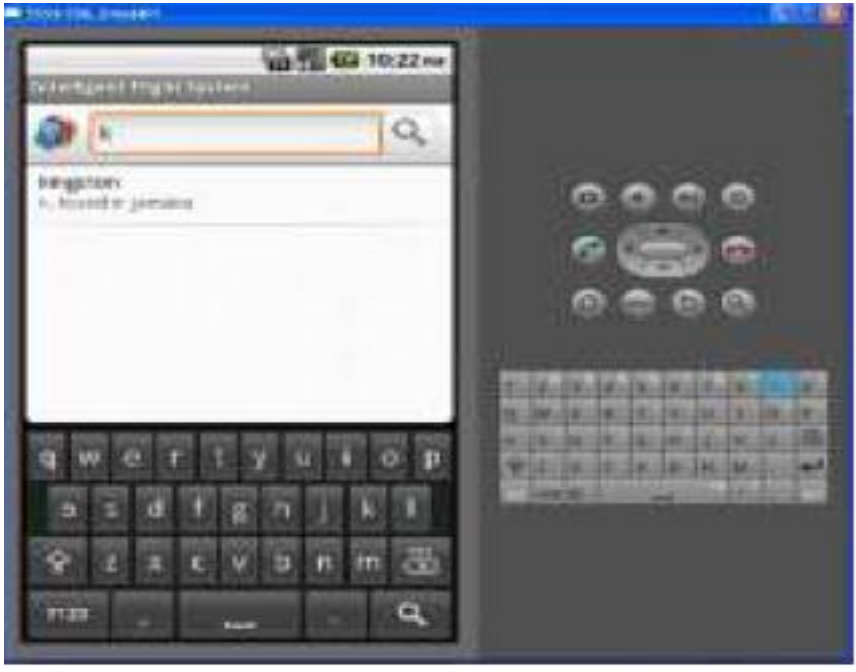

Figure.10 Departure City Wild Card Search

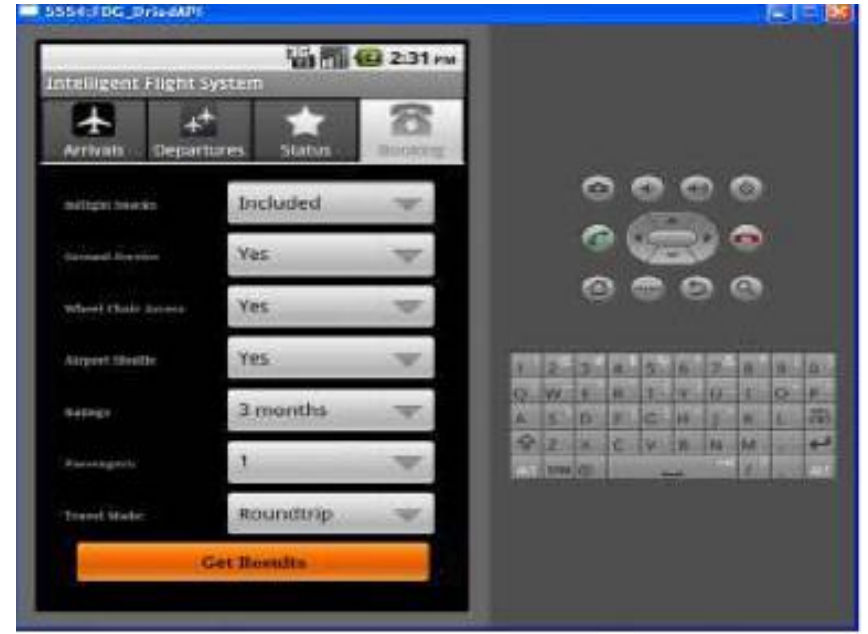

Figure. 11b Search Screen-1

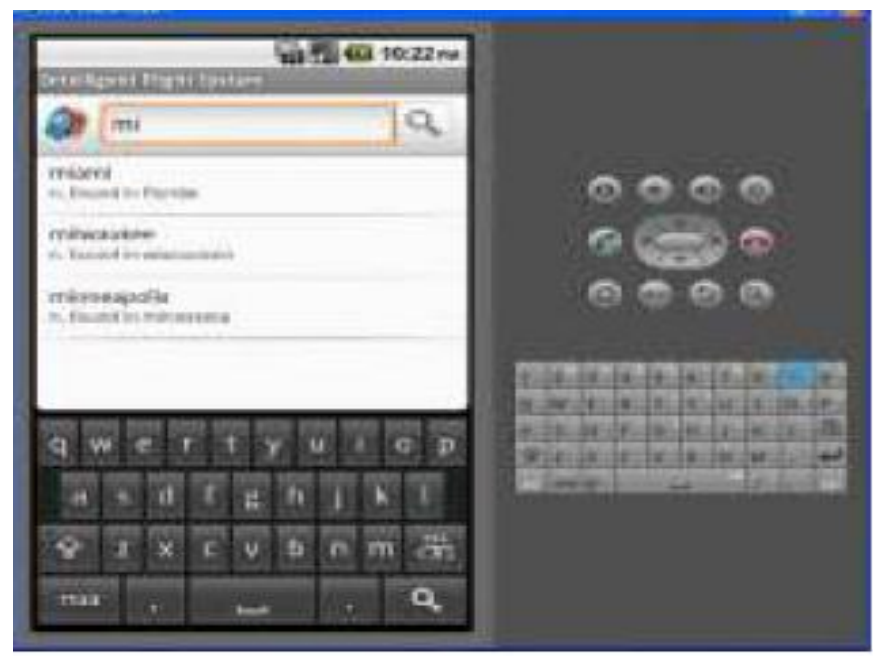

Figure.9 Arrival City Selection 


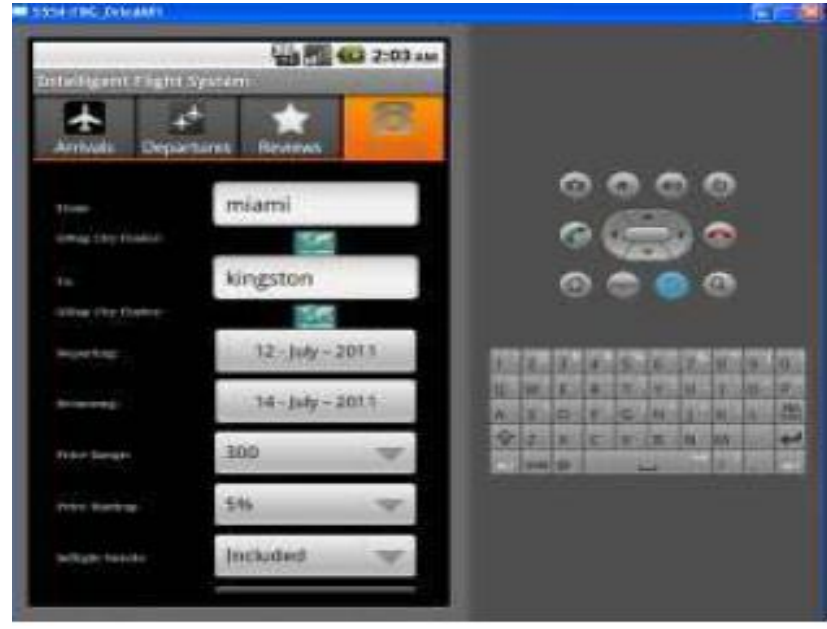

Figure. 11a Search Screen-1

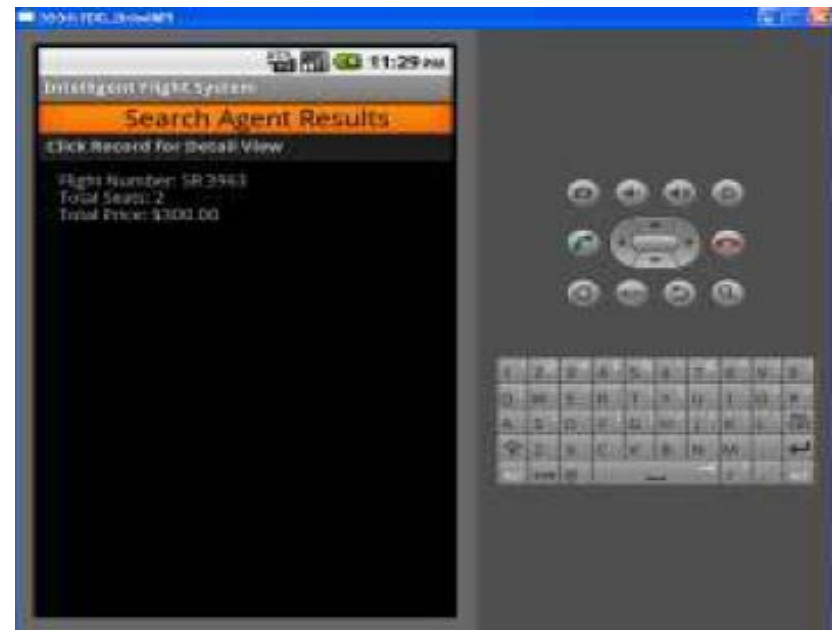

Figure. 12a Search Results-1

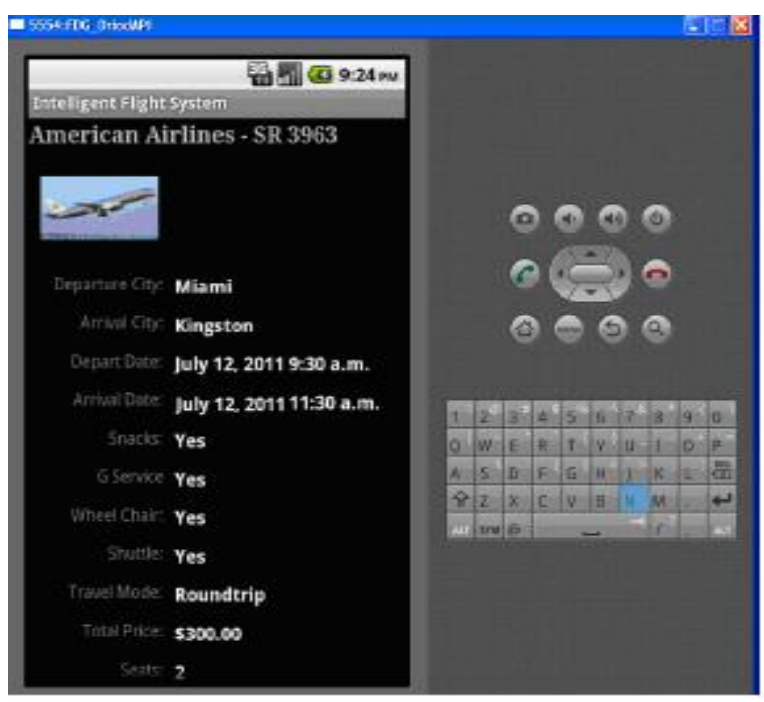

Figure.12b Detailed Results-1

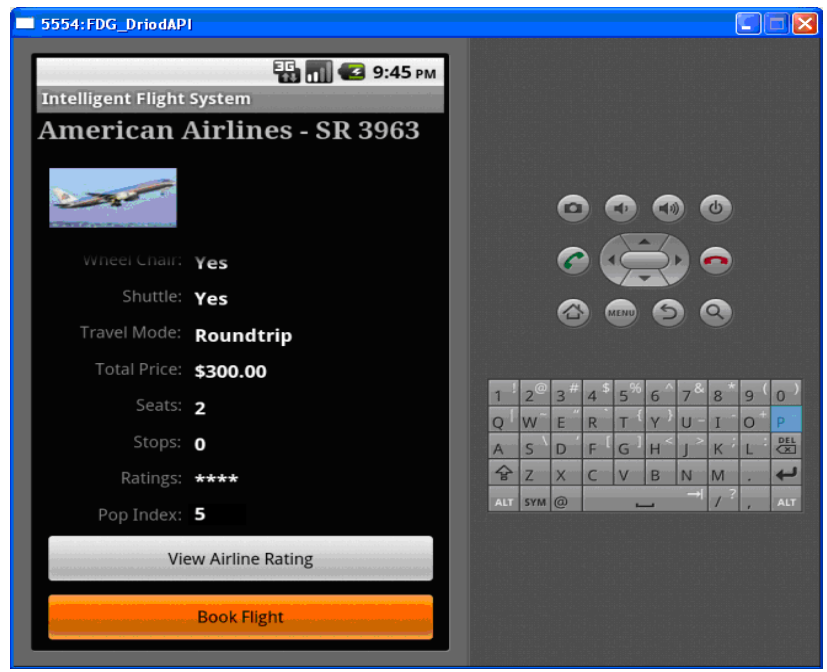

Figure.12c Detailed View of Results-2

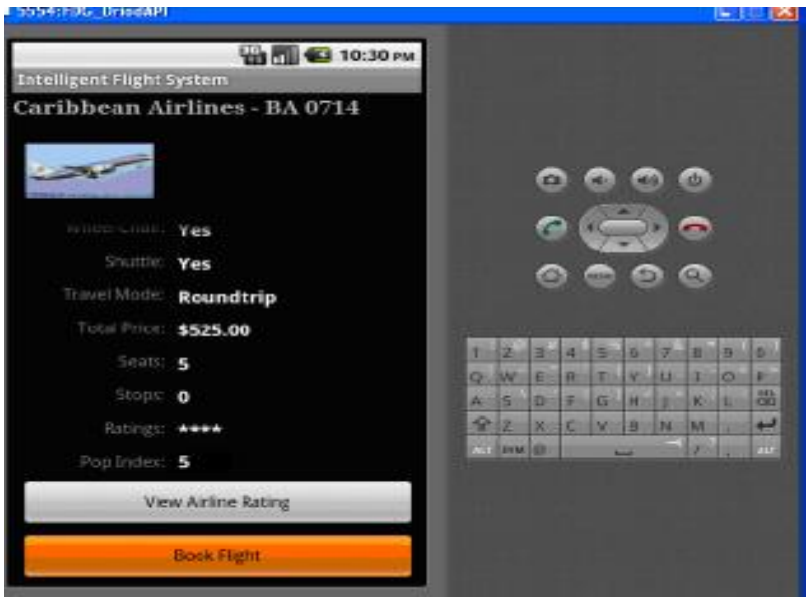

Figure.13b Detailed View of Results-3 


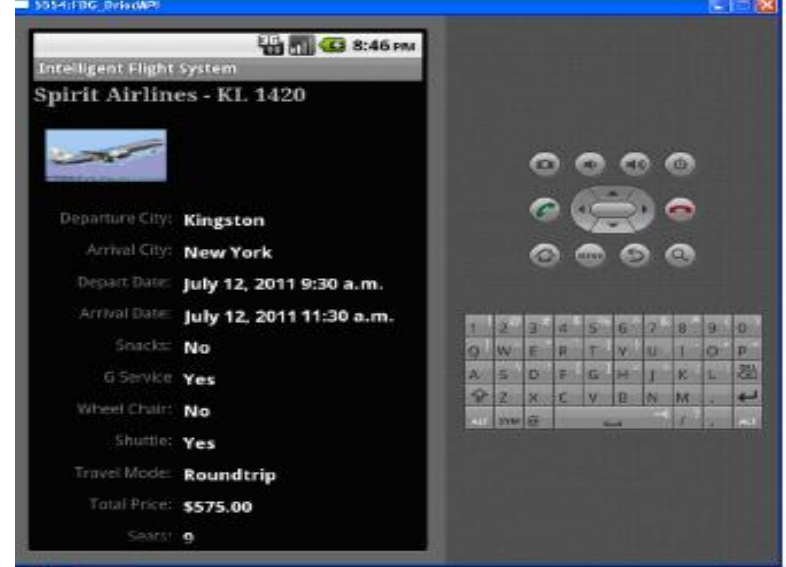

Figure.14a Detailed View of Results-5

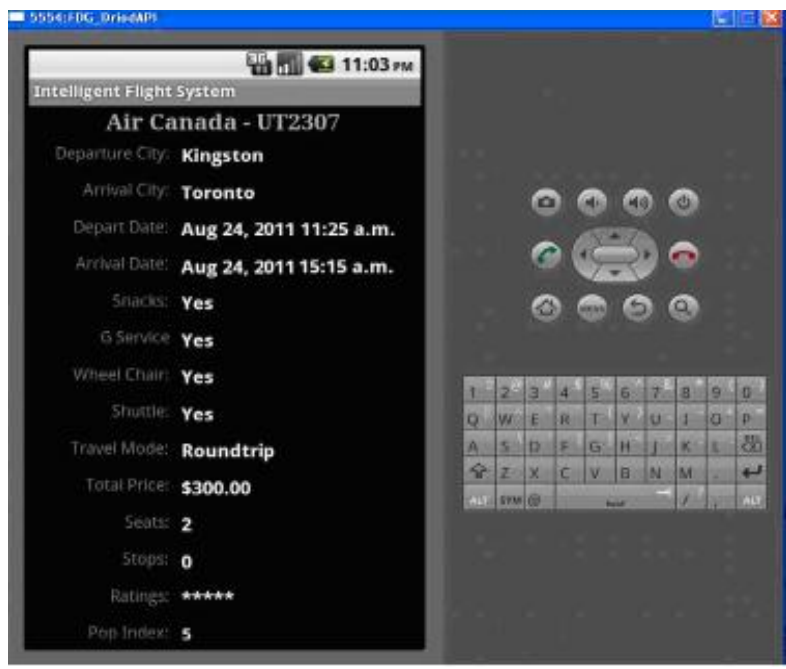

Figure.15 Detailed View of Results-7

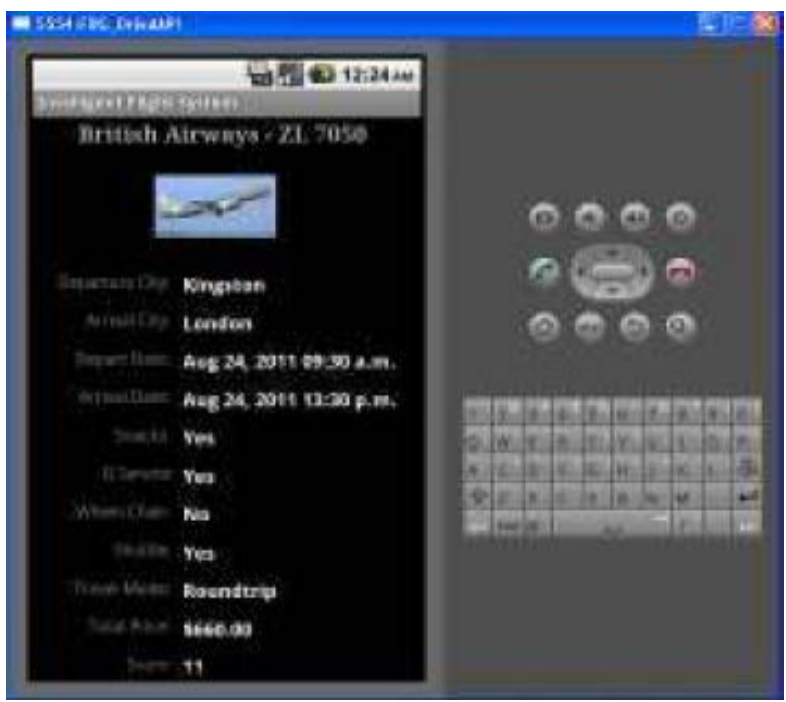

Figure.16b Detailed view of Results-9

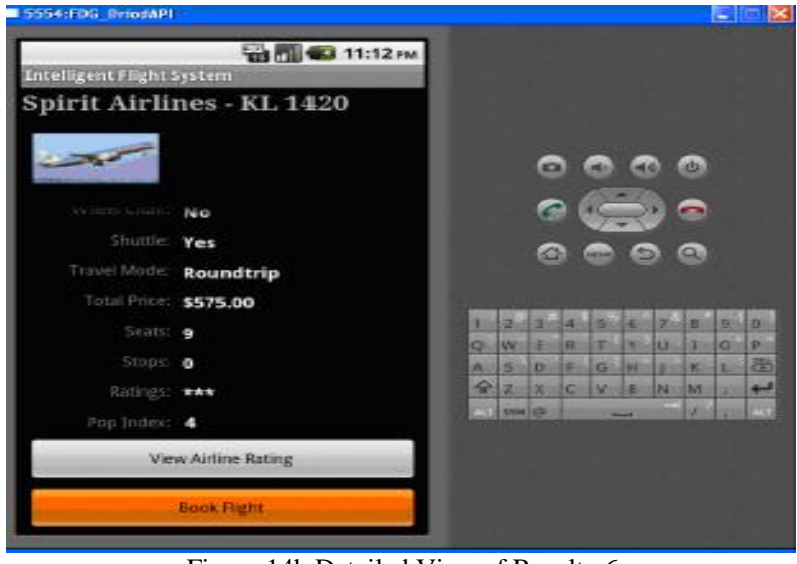

Figure.14b Detailed View of Results-6

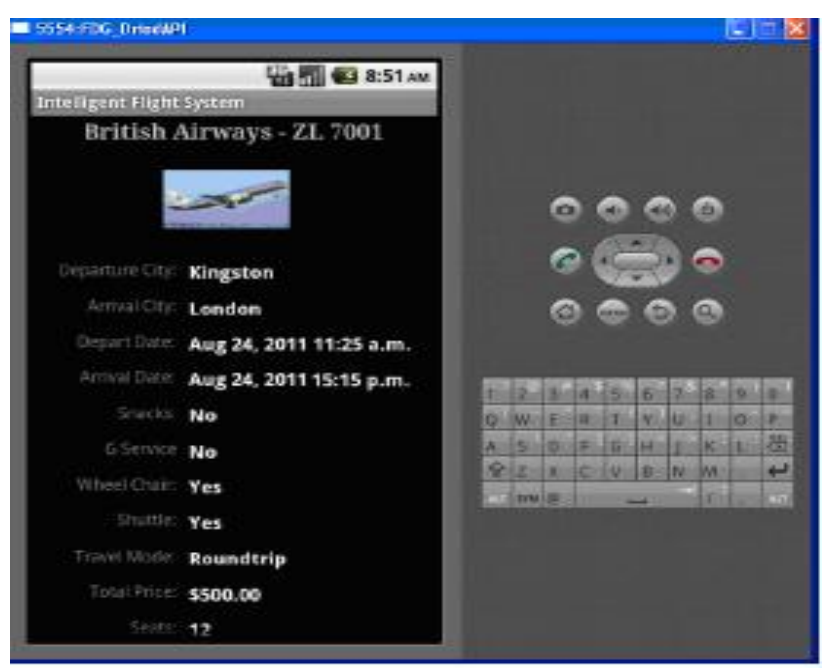

Figure.16a Detailed View of Results-8

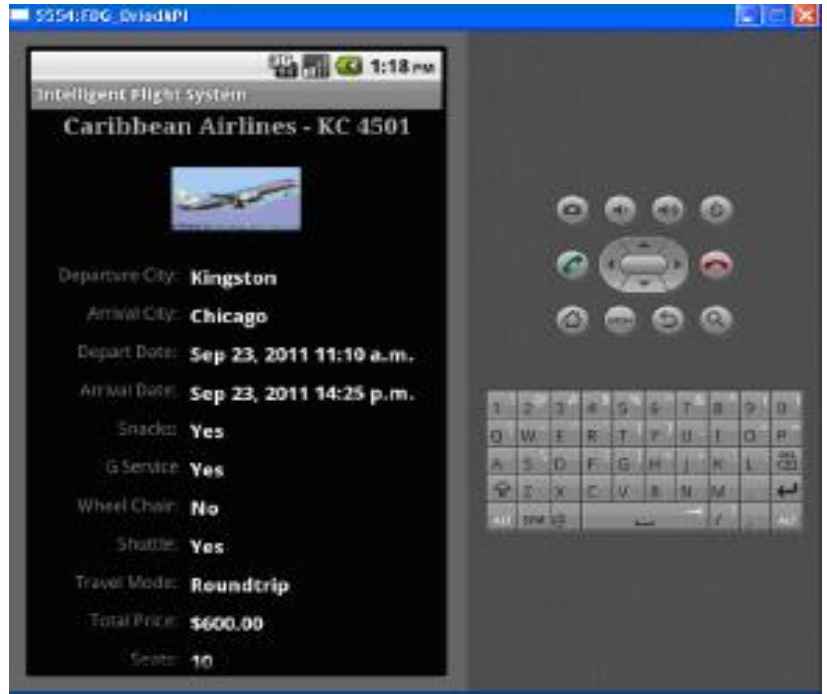

Figure.17a Detailed view of Results-10 


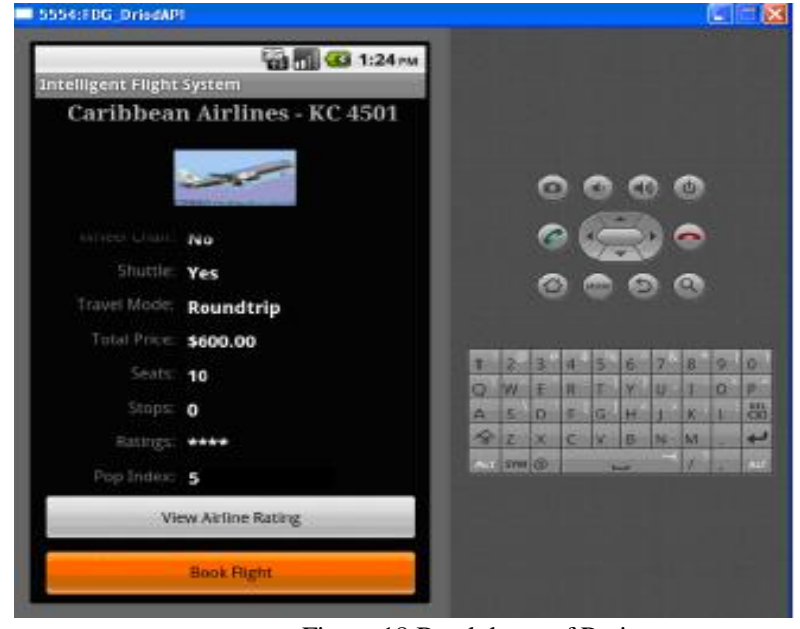

Figure.18 Breakdown of Rating

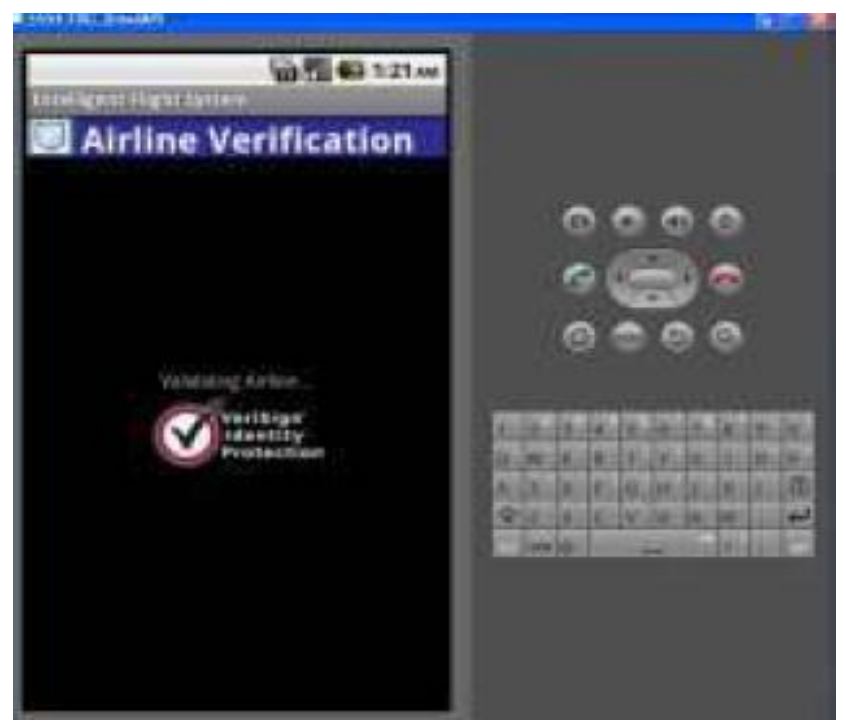

Figure.20 Airline Verification

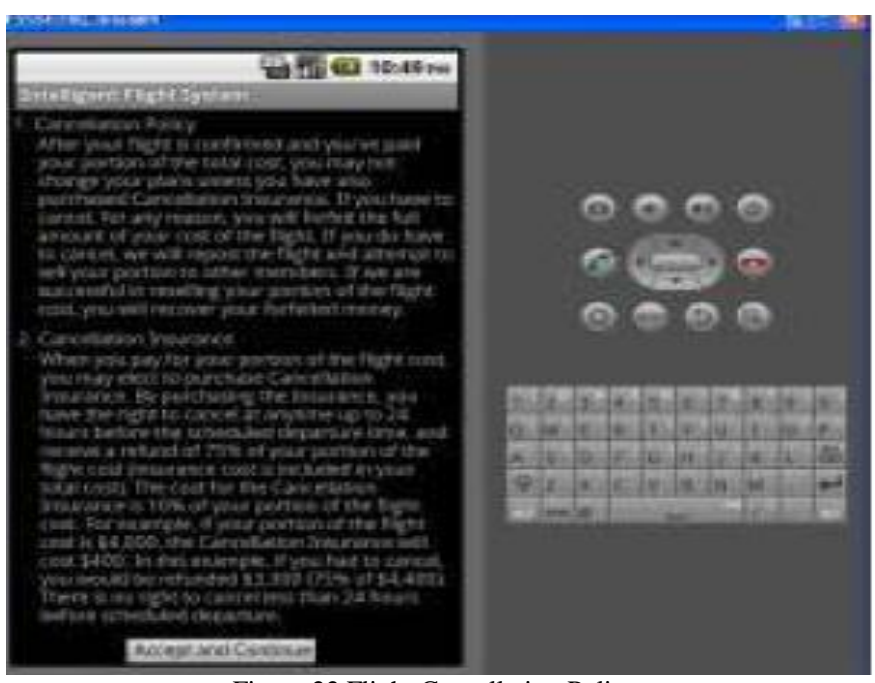

Figure.22 Flight Cancellation Policy

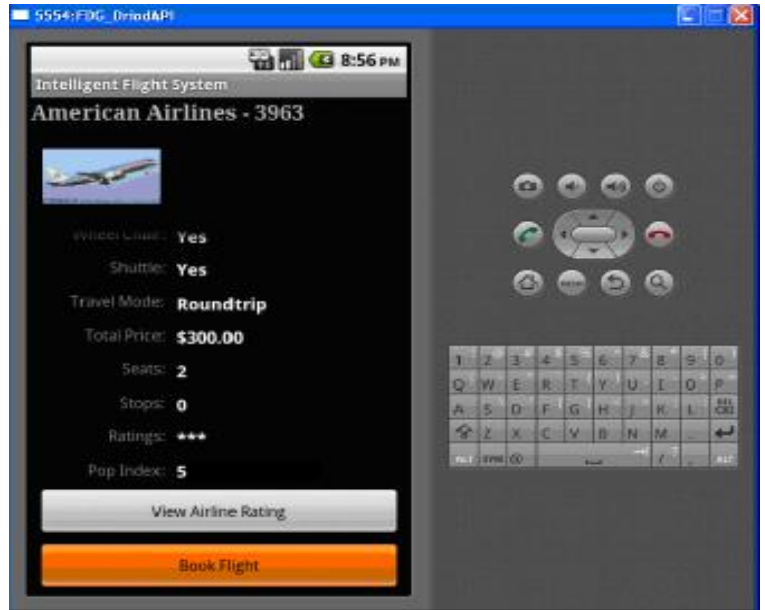

Figure.19 Book Flight Initiated

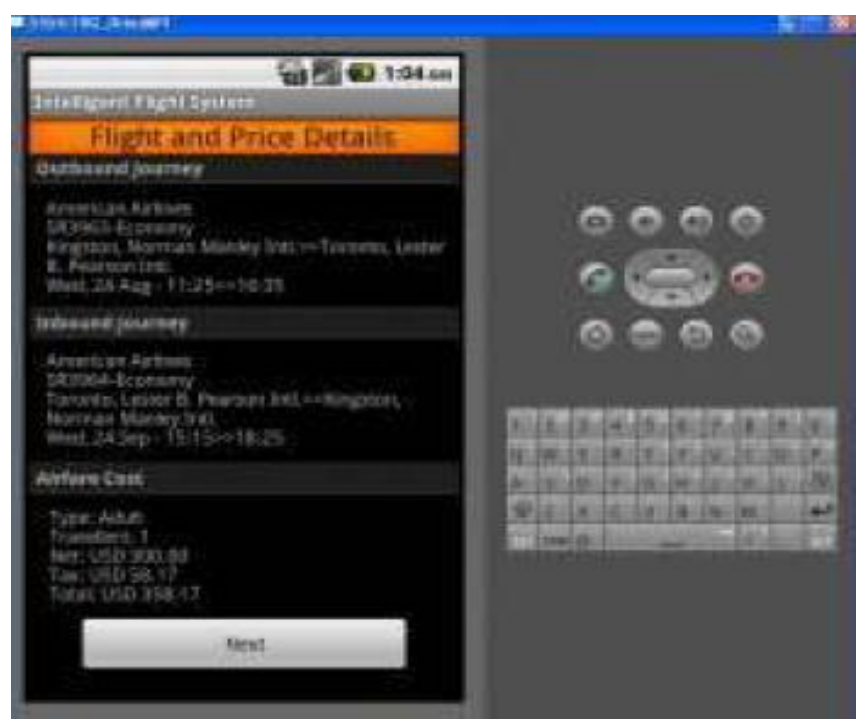

Figure.21 Flight Details for Verification

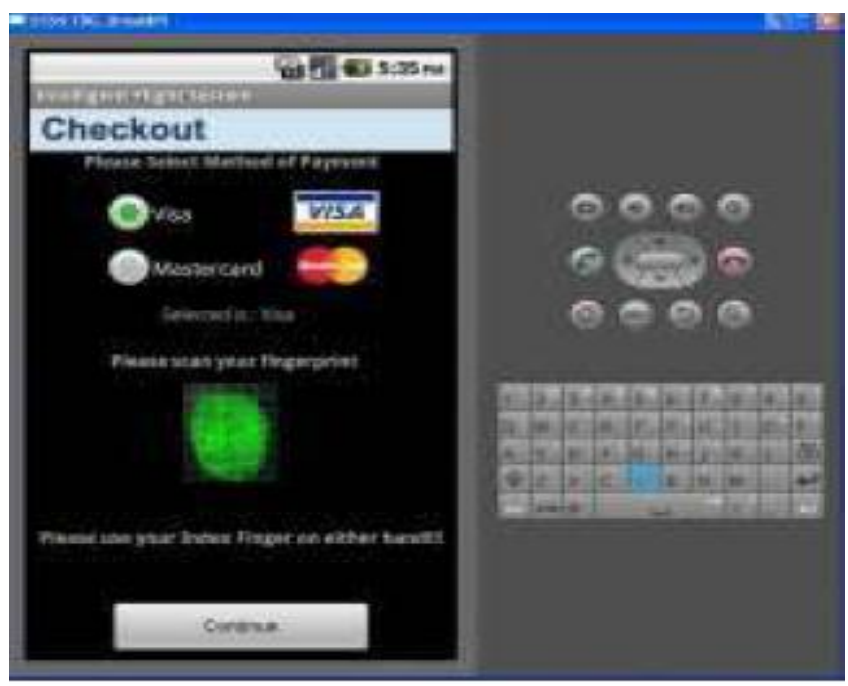

Figure.23 Financial Information 


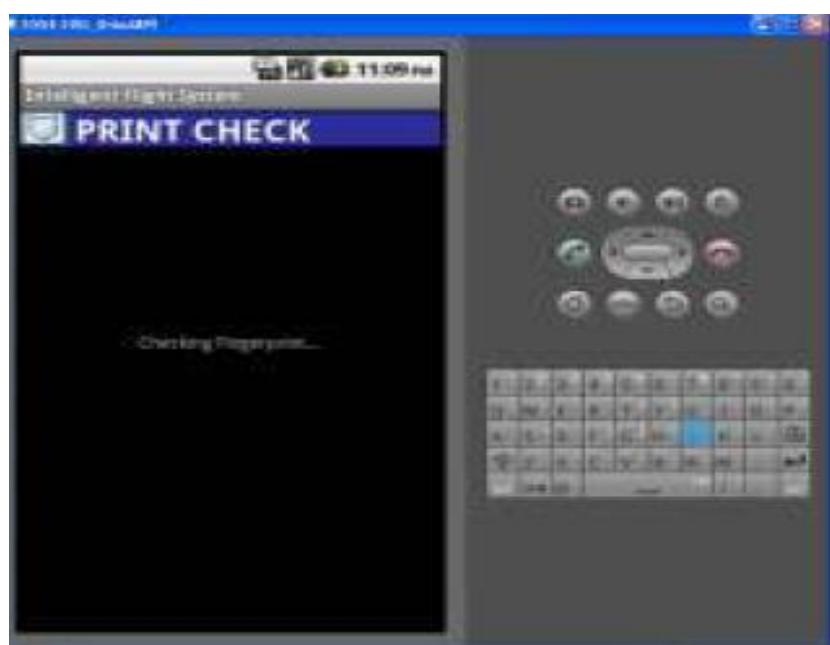

Figure.24 Fingerprint Checking

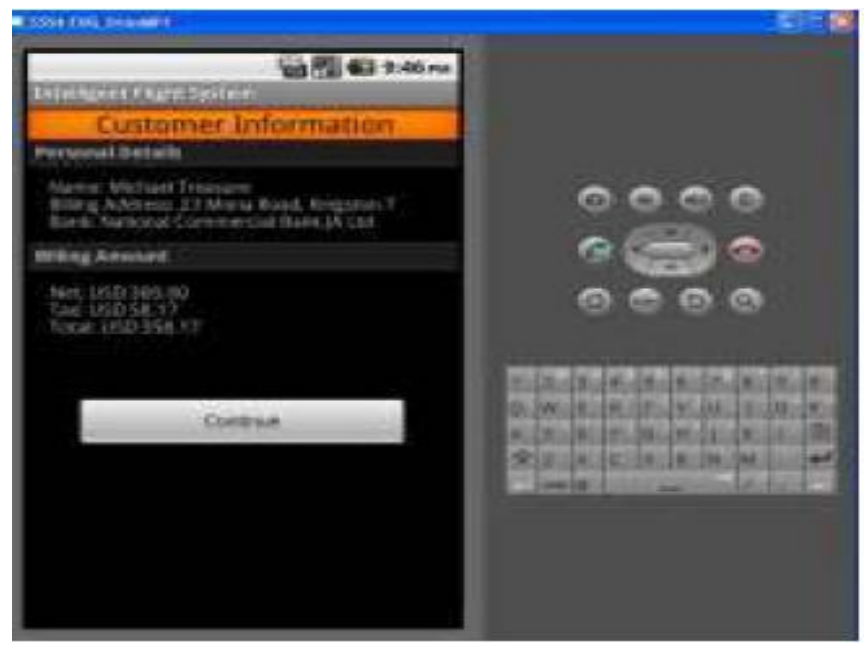

Figure.26 Payment Confirmation

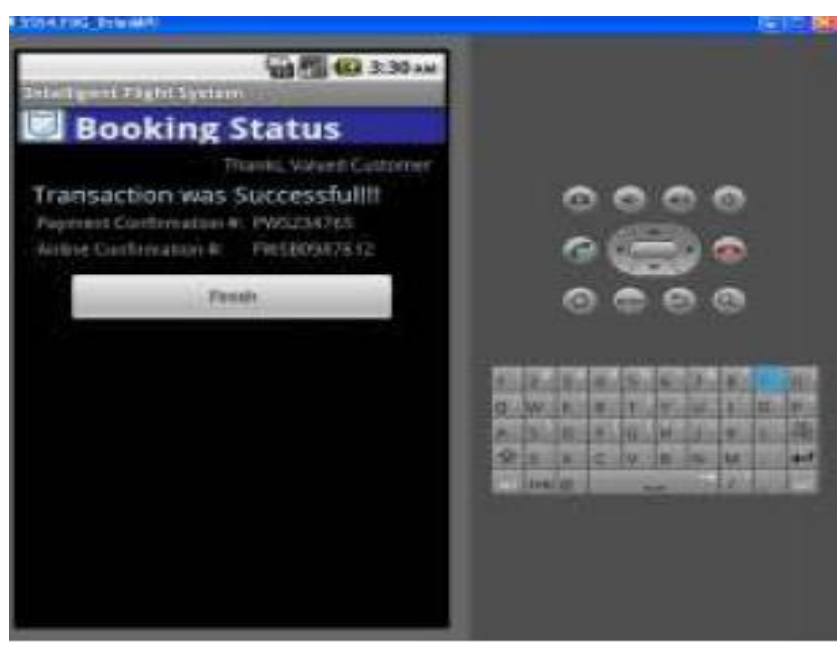

Figure.28 Payment Transaction

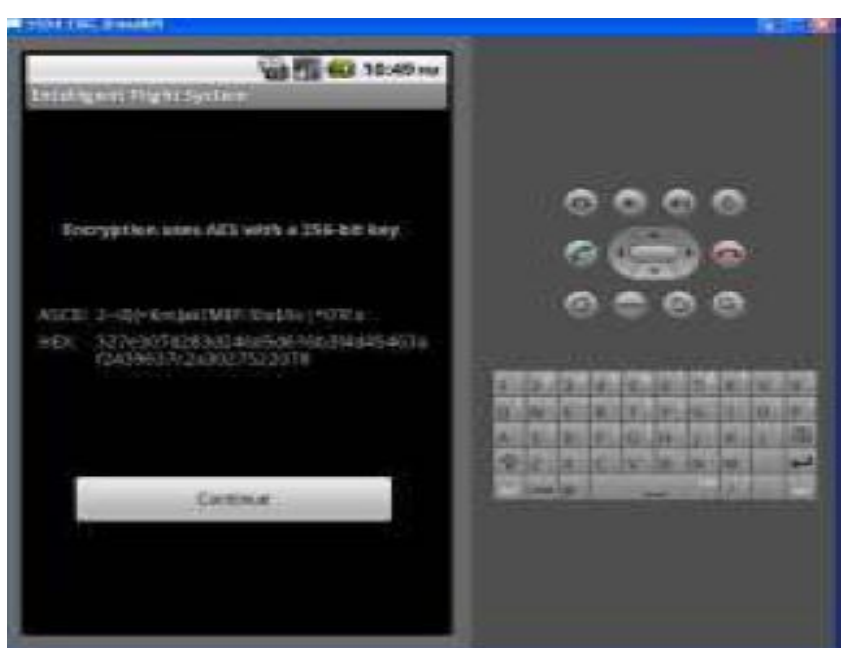

Figure.25 Fingerprint Encrypted

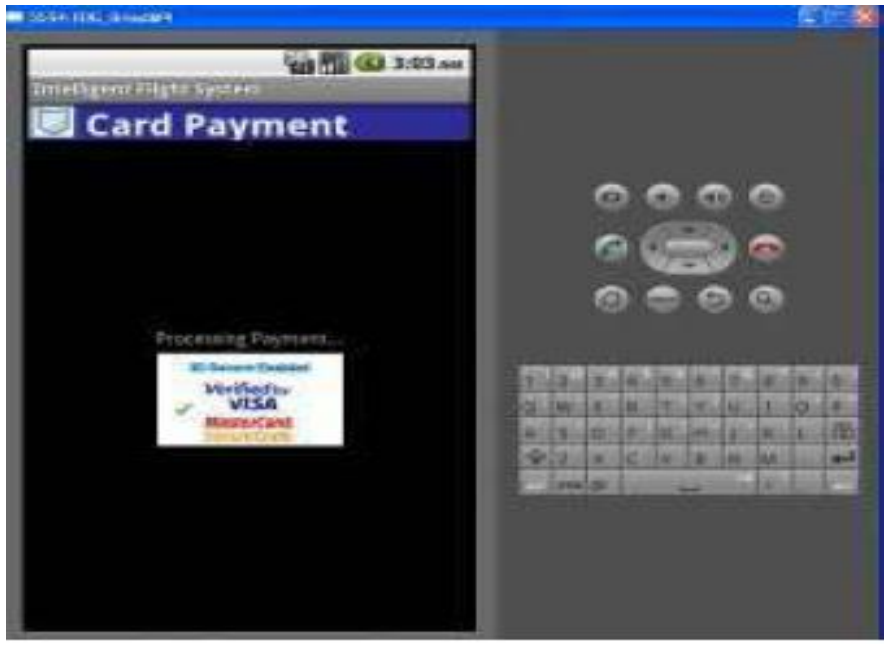

Figure.27 Payment Processing

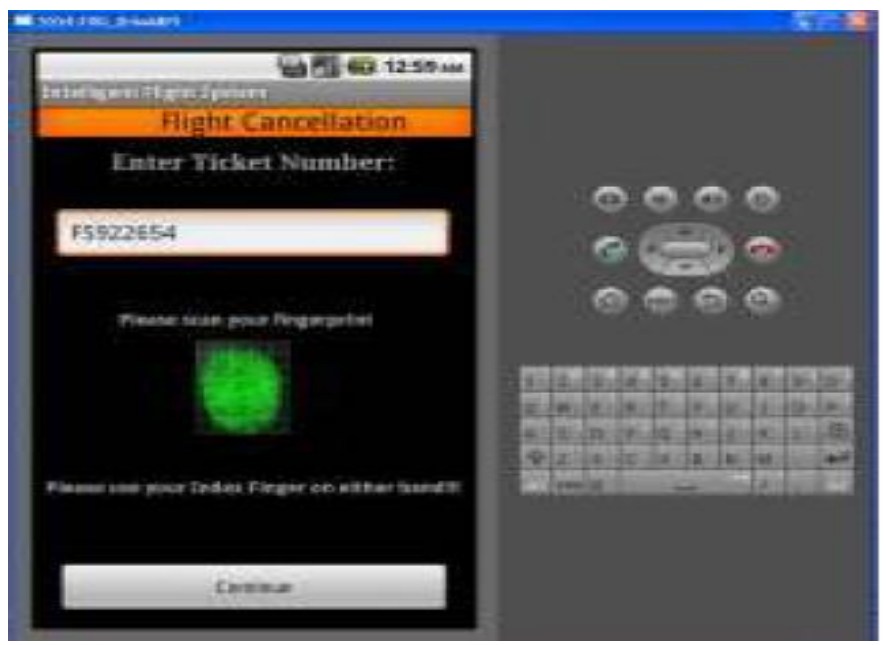

Figure.29 Ticket Cancellation 


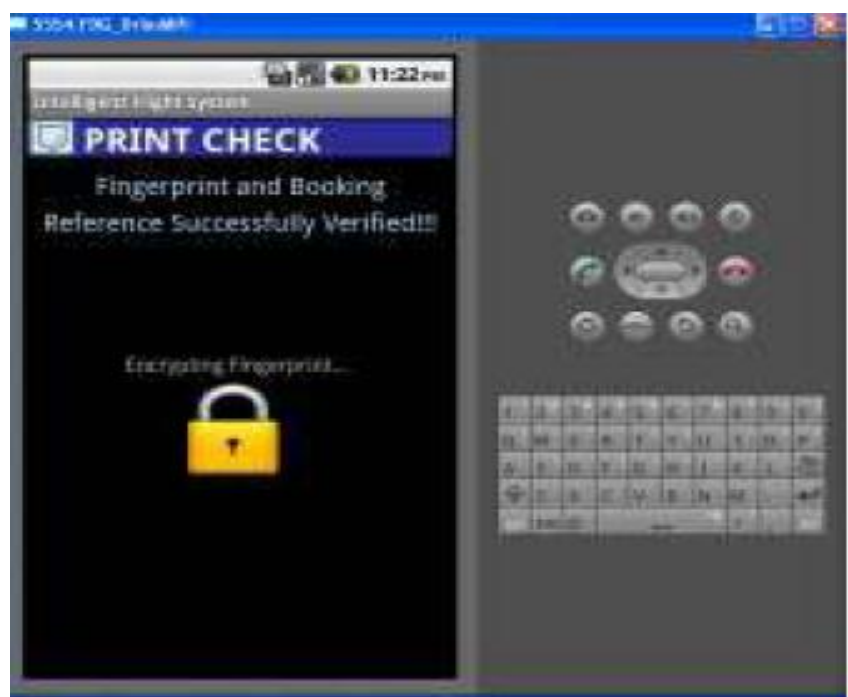

Figure.30 Fingerprint and Booking Validation

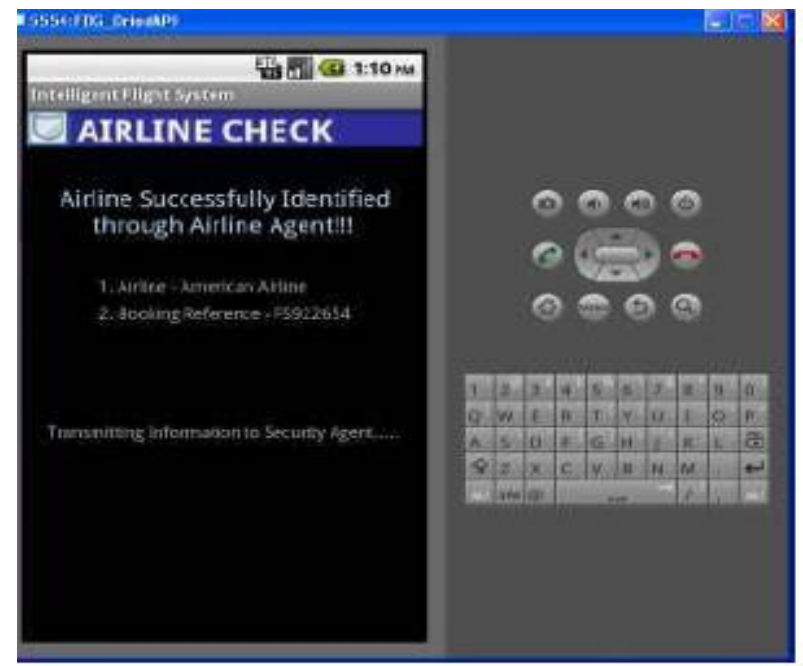

Figure.32 Security Agent Transmission

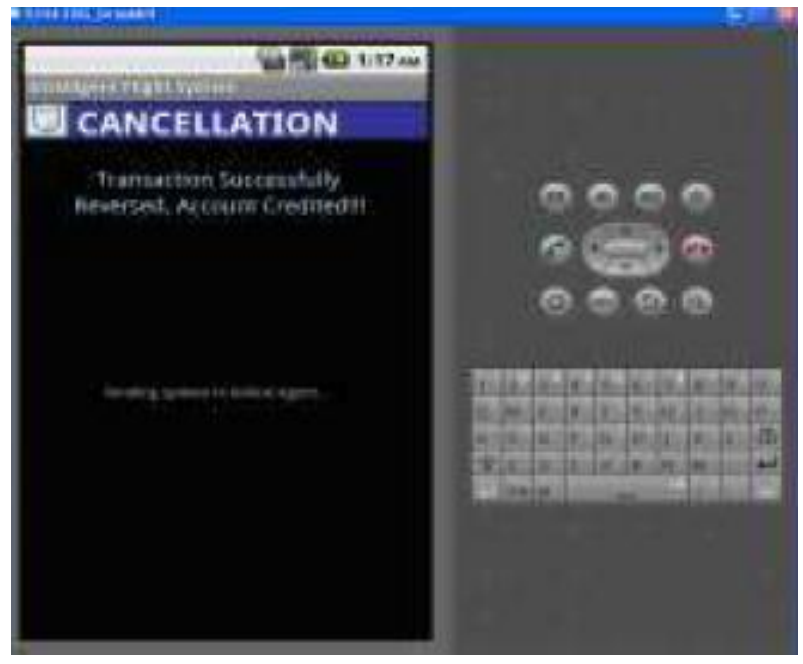

Figure. 34 Flight Cancelled

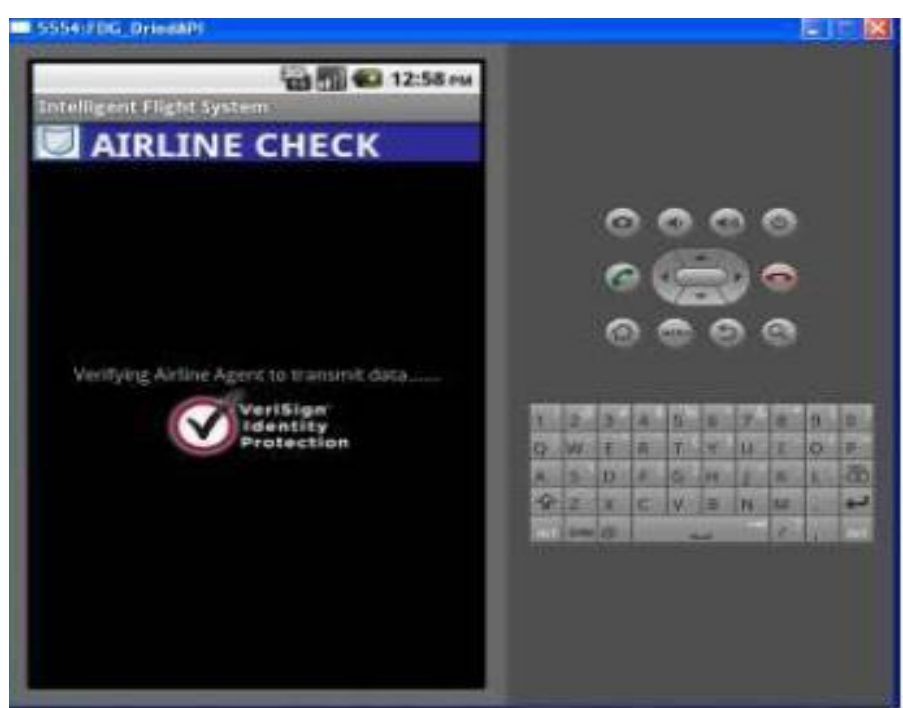

Figure.31 Airline Agent Verification

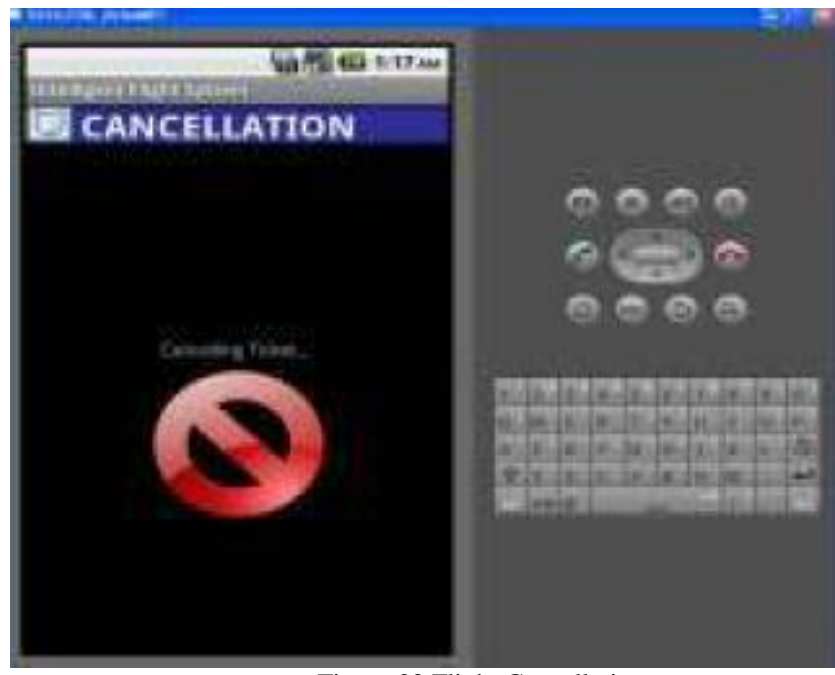

Figure.33 Flight Cancellation

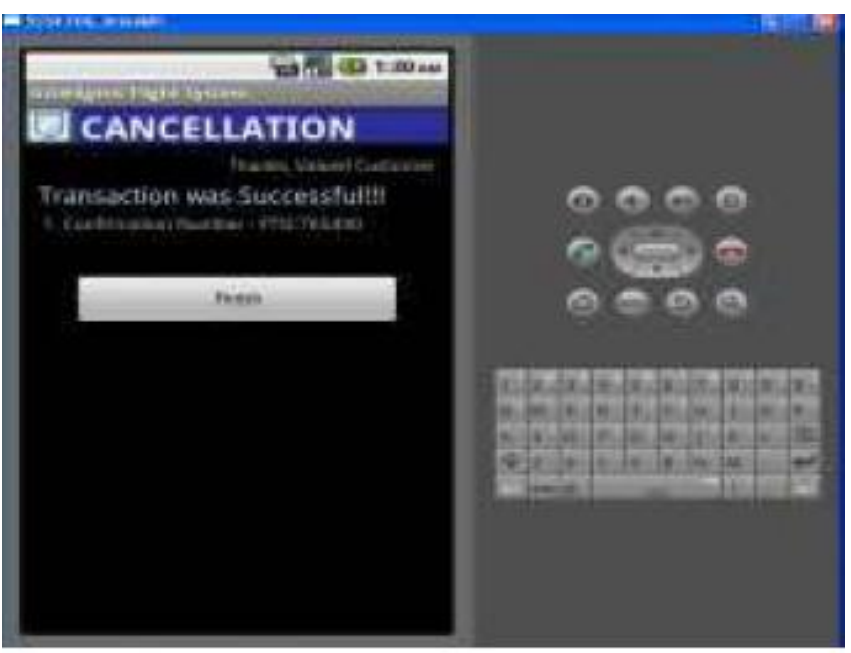

Figure.35 Flight Cancellation Status 


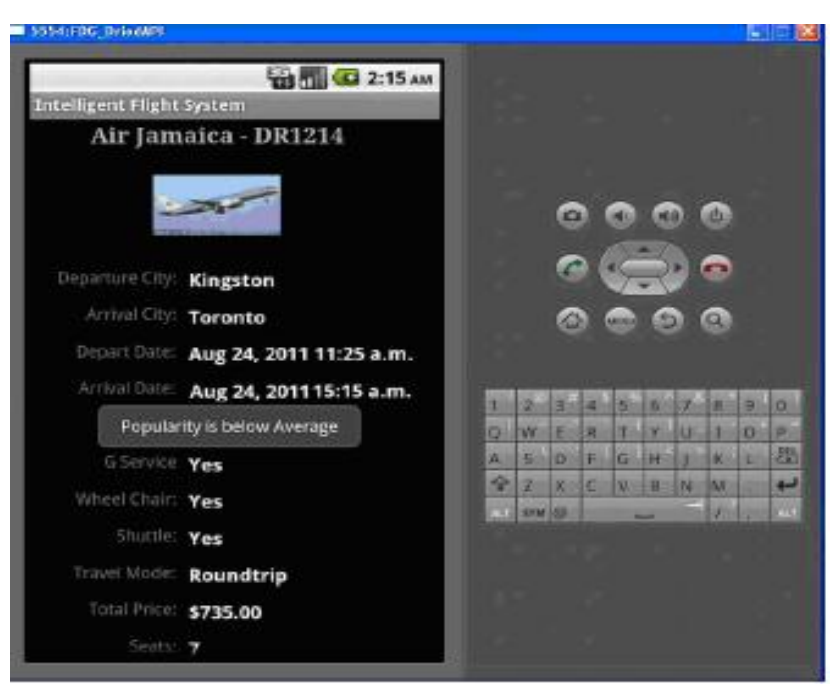

Figure.36 Results with Low Popularity

\section{REFERENCES}

[1] Information, Technology and Tourism. (2009). Retrieved from http://EzineArticles.com/3292939

[2] Computer Researvation System. (2004). Retrieved from http://www.cbo.gov/ftpdocs/55xx/doc5541/doc02b-part_4.pdf

[3] Videcom Airline Reservation System. (2004). Retrieved from http://www.videcom.com/general_overview.htm

[4] Travellers Warning. (2011). Retrieved,from http://www.computerworld.com.au/article/405074/scamwatchj_warns_tr avellers_fake_flight_booking_sites

[5] Garvey (2011). "Secured Agent based Mobile Airline Search and Secured Booking system", Unpublished M.Sc Dissertation, Department of computing, University of WestIndies, Jamaica

[6] Michaelides, A., \& Moraitakis, N. (1997). Intelligent Software Agents in Travel Reservation Systems

[7] Franklin, S., \& Graesser, A. (1996). Is it an Agent, or just a Program?: A Taxonomy for Autonomous Agents. Third International Workshop on Agent Theories Architectures and Languages. Springer-Verlag

[8] Pincemaille, C. (2008). Intelligent Agent Technology Institute of Technology, Ireland, Bishopstown, 2008

Cork

[9] Russell S, Norvig P (1995) Artificial Intelligence: A Modern Approach, Prentice Hall Series in Artificial Intelligence. Englewood Cliffs, New Jersey

[10] Wooldridge \& Jennings. (1995). Intelligent Agents: Theory And Practice. The Knowledge Engineering Review, Vol. 10:2, Pp 115-152

[11] Machine Learning. (2011). Retrieved from http://en.wikipedia.org/wiki/Machine_learning

[12] Mitchell, T. (1997). Machine Learning. McGraw Hill

[13] Hannan, J. F. (1957). Approximation to Bayes risk in repeated plays. Contributions to the Theory of Games, 3:97-139.

[14] Blackwell, D. (1956). Controlled random walks. In Proceedings of the International Congress of Mathematicians, volume 3, pages 336-338. North-Holland

[15] Fudenberg, D. and Levine, D. (1995). Universal consistency and cautious fictitious play. Journal of Economic Dynamics and Control, 19:1065-1089

[16] Young, H. P. (2004). Strategic Learning and Its Limits. Oxford University Press.

[17] Kaelbling, L. P., et al (1996). Reinforcement learning: A survey. Journal of Artificial Intelligence Research, 4:237-285.

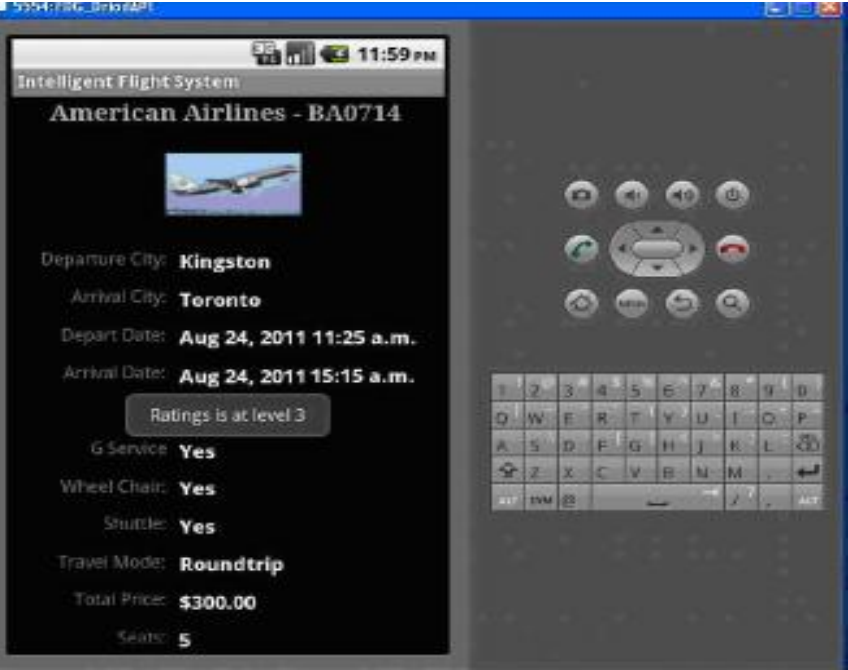

Figure.37 Results with low Rating

[18] Shoham, Y., Powers, R., and Grenager, T. (2004). On the agenda(s) of research on multi-agent learning. In AAAI 2004 Symposium on Artificial Multi-Agent Learning [FS-04-02]. AAAI Press.

[19] Sutton, R. S. and Barto, A. G. (1998). Reinforcement Learning: An Introduction. MIT Press

[20] Alonso, E., \& Inverno, M., D., (2001). Learning in multi-agent systems, UK:Cambridge University Press.

[21] Artificial Intelligence. (1996). Retrieved from http://www.cs.washington.edu/homes/lazowska/cra/ai.html

[22] Travel Agents. (2001). Retrieved from http://www.asta.org/about/content.cfm?ItemNumber=1985\&navItemNu mber $=515$

[23] Biometrics. (1998). Retrieved from http://searchsecurity.techtarget.com/definition/biometrics

[24] Pfitzmann, B., \& Sadeghi, A.-r. (1996). Anonymous fingerprinting. Berlin: Springer-Verlag

[25] Jain, A., et al. (1997). On-Line Fingerprint Verification. IEEE Transactions on Pattern Analysis and Machine Intelligence VOL. 19, No. 4, 302-305.

[26] O'Gorman, L. (1999). Fingerprint Verification. New Jersey: Verdicom Inc

[27] .William, S. (2005). Cryptography and Network Security Principles and Practices, Fourth Edition. Prentice Hall

[28] Bellifemine, F., et al. (2007). Developing multi-agent systems with Jade. John Wiley \& Sons, Ltd

[29] Android. (2011). Retrieved from http://developer.android.com/guide/basics/what-is-android.html

[30] .Moreno et al. (2003). Using JADE-LEAP to implement agents in mobile devices. Retrieved from http://jade.tilab.com/papers/Exp/02Moreno.pdf.

[31] Morris, J., (2011). Android User Interface Development. 32 Lincoln Road, Olton, Birmingham, UK: Packt Publishing Ltd.

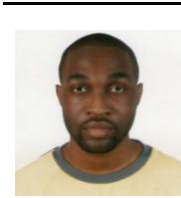

AUTHORS PROFILE

Floyd Garvey is a final year M.Sc. Computer Science student in the Department of Computing at the University of the West Indies, Jamaica since 2009 and also a Bachelor's degree in Management Information system. His e also a Microsoft certified professional. He started his professional career during 2003 as System/Network Administrator in Smith \& Steward Distributions Ltd. Later during 2005-2008 he was working as IT administrator in Jamaica in the Theological Seminary \& Caribbean Graduate School of Theology. And the during 2008-2011 he was working as System Support office in Bank of Novo Scotia Jamaica and presently working as 
Senior System Support Analyst in Scotia Bank, Ontario, Canada. In his Master's Programme he did Master's thesis on Secure Agent based Airline Search and Booking system which focused on using intelligent agents to search, the airlines based on user requirements and also booking the flights online securely suing biometrics. His research interest includes Intelligent Agents, Mobile commerce, Robotics, Nanotechnology and Neural Networks.

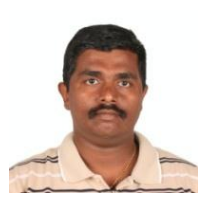

Dr. Suresh Sankaranarayanan holds a PhD degree (2006) in Electrical in Networking from the University of South Australia. Later he has worked as a Postdoctoral Research Fellow and then as a Lecturer in the University of Technology, Sydney and at the University of Sydney, respectively during 2006-08. He is a Senior Member of IEEE computer Society and Computer Society of India. He was working as a Lecturer (Asst. Prof. Status) in the Department of
Computing and lead the Intelligent Networking Research Group, in the University of West Indies, Kingston, Jamaica, during 2008-11.He has also worked as a Professor, School of Computer Science and Engineering, Vellore Institute of Technology (VIT University), Chennai Campus, India, for a short period during 2011. He is now working as Associate Professor, Department of Computer \& Information Systems, Institute of Technology, Brunei (ITB - A technological university). Currently he is also functioning as a Visiting Professor, Department of computing, Faculty of Pure \& applied Science, University of West Indies, Mona Campus, Kingston-7, Jamaica, West Indies. $\mathrm{He}$ has supervised more than 25 research students leading to M.Sc, ME, M.Phil and M.S degrees and currently supervising 6 students leading to M.Sc, M.Phil and $\mathrm{PhD}$ respectively. He has got to his credit, as on date, about 50 fully refereed research papers published in the Proceedings of major IEEE international conferences, as Book Chapters and in International Journals. 